\title{
POTENCIAL DE USO DO MODELO CENTURY E SIG PARA AVALIAR O IMPACTO DA AGRICULTURA SOBRE ESTOQUES REGIONAIS DE CARBONO ORGÂNICO DO SOLO(1)
}

\author{
Elisandra Solange Oliveira Bortolon( ${ }^{(2)}$, João Mielniczuk ${ }^{(3)}$, Carlos \\ Gustavo Tornquist ${ }^{(3)}$, Fabíola Lopes ${ }^{(4)}$, Élvio Giasson ${ }^{(3)}$ \& Homero \\ Bergamaschi ${ }^{(5)}$
}

\begin{abstract}
RESUMO
O uso e as mudanças no uso e manejo dos solos figuram entre os principais fatores determinantes dos estoques de carbono orgânico do solo (COS). A modelagem dinâmica espacialmente explícita é uma técnica que vem sendo usada com sucesso em avaliações das alterações nos estoques regionais de COS. Assim, este trabalho objetivou utilizar o modelo Century associado a técnicas de geoprocessamento e sensoriamento remoto para avaliar os efeitos das alterações do uso agrícola e manejo do solo na dinâmica do carbono orgânico do solo (COS) em propriedades rurais do Distrito Santana, Ijuí - RS. Para isso, foi criada uma base de dados geoespaciais em ambiente ArcGis9.x com os planos temáticos: solos, elementos da paisagem e início do uso agrícola. Após reconstituídos os cenários históricos de manejo, o modelo Century 4.0 foi inicializado com dados edafoclimáticos locais, calibrado em duas etapas e validado, obedecendo-se à seguinte ordem: calibração principal - validação - calibração para generalizações. Na calibração principal, foram ajustados parâmetros internos do modelo, valendose da adição de carbono (C) pelo milho, trigo e soja e dos estoques de COS medidos em 2007 na camada de 0 a $20 \mathrm{~cm}$ da mata nativa e de uma lavoura adjacente, cuja conversão ocorreu entre 1901 e 1930 (lavoura mais antiga, localizada na área 1), sob Latossolo de topo. Em seguida, o Century, assim ajustado, foi estatisticamente validado com base em dados observados em 10 lavouras iniciadas em diferentes épocas, sob a mesma classe de solo e posição na paisagem, amostradas em 2007 na camada de 0 a $20 \mathrm{~cm}$ e distribuídas em quatro áreas homogêneas (áreas 1, 2, $3 \mathrm{e}$ 4) dentro do Distrito Santana. Na calibração para generalizações, foram criadas
\end{abstract}

(1) Parte da Tese de Doutorado do primeiro autor, apresentada ao Programa de Pós-Graduação em Ciência do Solo, Faculdade de Agronomia, Universidade Federal do Rio Grande do Sul - UFRGS. Projeto financiado pelo PRONEX - FAPERGS-CNPq-MCT, No 08450-0. Recebido para publicação em 13 de agosto de 2011 e aprovado em 14 de fevereiro de 2012.

(2) Pós-Doutoranda do PPG-Ciência do Solo, Universidade Federal do Rio Grande do Sul - UFRGS. Av. Bento Gonçalves 7712 , CEP 91540-000 Porto Alegre (RS). Bolsista do CNPq. E-mail: elisandra.oliveira@ufrgs.br

(3) Professor do Departamento de Solos, UFRGS. E-mails: joaomiel@terra.com.br; carlos.tornquist@ufrgs.br; giasson@ufrgs.br

(4) Doutora em Ciência do Solo. E-mail: fabilopes@gmail.com

(5) Professor do Departamento de Plantas Forrageiras e Agrometeorologia, UFRGS. E-mail: homerobe@ufrgs.br 
quatro opções de "floresta subtropical" para representar a mata nativa de cada classe de solo em estudo (Latossolo, Chernossolo, Neossolo Regolítico e Neossolo Flúvico), a partir da opção de floresta tropical gerada na etapa de calibração principal, mantendo-se os ajustes já realizados naquela etapa e alterando apenas o parâmetro referente à máxima produção bruta mensal de biomassa pela floresta para que a variável de saída SOMTC (COS simulado) se estabilizasse, após o modelo ser executado por 3.000 anos (execução de equilíbrio), coincidindo com os estoques de COS medidos no solo sob vegetação nativa respectiva de cada classe de solo; em seguida, procedeu-se às simulações correspondentes a 54 unidades de simulação (US), por meio da interface i-Century, nas condições de solos cultivados com os cenários de manejo históricos (de 1901 até 2007). O Century, depois de calibrado, estimou adequadamente a dinâmica do $\mathrm{C}$, reproduzindo a evolução dos estoques de COS ocorrida no Distrito Santana. Segundo essas estimativas, a adoção de práticas conservacionistas de manejo garante a redução das perdas de $\mathbf{C}$ causadas pelo processo erosivo e decomposição microbiana, havendo com isso aumento no estoque de COS.

Termos de indexação: matéria orgânica do solo, modelagem do C, modelagem dinâmica espacialmente explícita, sistemas de manejo do solo.

\section{SUMMARY: POTENTIAL USE OF CENTURY MODEL AND GIS TO EVALUATE THE IMPACT OF AGRICULTURE ON REGIONAL SOIL ORGANIC CARBON STOCKS}

The land use and land use and management changes are among the main determinants of the stocks of soil organic carbon (SOC). The spatially explicit dynamic modeling is a technique that has been successfully used in evaluations of regional SOC stocks changes. Thus, this study aimed to use the Century 4.0 model associated with geoprocessing and remote sensing techniques to evaluate the effects of agricultural use and soil management changes on dynamics of soil organic carbon (SOC) on farms in Santana (Ijui, RS, Brazil). A geospatial database of the thematic plans: soil classes, land cover, landforms and beginning of agricultural use, were created in ARCGIS 9.x. After land use and soil management systems had been reconstituted from historical and current surveys, the model was initialized with local soil and climate data and calibrated in two steps. In the first calibration step, internal model parameters based on maize, wheat and soybean biomass $C$ additions to the soil were adjusted, as well as SOC measured in 2007 (0-20 cm layer) of native forest (original condition) and an adjacent farm, where agriculture had been initiated between 1901 and 1930 (older plantation, area 1), sampling an Oxisol, on hilltops. Afterwards, the Century model was statistically validated based on data from 10 fields, initiated at different times, with the same soil type and landscape, sampled in 2007 (0-20 cm layer) divided into four homogeneous areas (Areas 1, 2, 3 and 4) within the district of Santana. In the calibration for generalization, four "subtropical forest "options were created to represent the native forest of each soil type in (Oxisol, Mollisol and two Entisol types) based on the tropical forest option generated in the primary calibration step; the adjustments of this step were maintained and only the parameter related to maximum gross monthly production of forest biomass was changed to stabilize the output variable SOMTC (simulated SOC), after running the model for 3000 years (equilibrium run), matching the measured SOC stocks of each soil type under native vegetation. After calibration, all possible combinations of soils, landforms, land use cover and land use change for the agricultural use of Santana ((1901 to 2007; 54 simulation units) were simulated by the $i$-Century interface. The model estimated the $C$ dynamics adequately, reproducing the evolution of SOC stocks in the area. According to the estimates, the adoption of conservation management practices ensures the reduction of $C$ losses caused by erosion and microbial decomposition, resulting in increases in SOC stocks.

Index terms: soil organic matter, carbon modeling, spatially explicit dynamic modeling, management systems. 


\section{INTRODUÇÃO}

A atual preocupação com as mudanças climáticas globais decorrentes do aumento nas concentrações de gases do efeito estufa na atmosfera, em especial do $\mathrm{CO}_{2}$, tem despertado a atenção da comunidade científica para o ciclo biogeoquímico do carbono (C), sendo a conversão de áreas de vegetação nativa em áreas destinadas à exploração agrícola apontada como um dos principais fatores responsáveis pelas emissões de C para a atmosfera (Lal., 2001).

Essas mudanças interferem na dinâmica da matéria orgânica do solo (MOS), podendo levar à redução dos estoques de $\mathrm{C}$ deste, também influenciada pelo tipo de manejo a que o solo é submetido (Mielniczuk et al., 2003; Bayer et al., 2006). Assim, métodos de monitoramento dos efeitos das mudanças no uso e manejo dos solos sobre os estoques de C são necessários e devem ser confiáveis, eficientes e de baixo custo, englobando a complexidade de processos físicos, químicos e biológicos envolvidos na sua dinâmica (Lal, 2002). Experimentos de longa duração têm sido utilizados com sucesso no estudo das alterações no carbono orgânico do solo (COS) em razão do uso e manejo a que este é submetido ao longo dos anos; contudo, eles são relativamente recentes se comparados ao início do uso agrícola dos solos. Nesse sentido, novas abordagens têm sido propostas, em que a modelagem dinâmica tem se mostrado promissora, visto que permite integrar os conhecimentos acerca da dinâmica da MOS, possibilitando a análise retrospectiva e prospectiva das alterações nos estoques de COS em função do uso e manejo do solo adotado pelos agricultores (Cerri et al., 2004; Leite et al., 2004; Lopes et al., 2008; Bortolon et al., 2009; Tornquist et al., 2009).

Entre as diferentes técnicas de modelagem do C, a modelagem dinâmica espacialmente explícita tem recebido destaque, pois, segundo Nørgaard (2004), permite a análise dos estoques de COS considerando a sua variação no tempo e no espaço, a partir da associação de estimativas de modelos dinâmicos (modelo Century, por exemplo) com a utilização de técnicas de geoprocessamento em ambiente SIG (Sistemas de Informações Geográficas). Essa técnica tem como principal vantagem permitir a análise espacializada da evolução temporal dos estoques de COS.

O modelo Century foi desenvolvido para simular a dinâmica da matéria orgânica em solos sob pastagens naturais e, posteriormente, adaptado para solos de florestas e sob diferentes explorações agrícolas. Ele permite a modelagem da dinâmica do carbono, nitrogênio, fósforo, enxofre, água, crescimento e produção de plantas nos mais diversos tipos de solo, clima e bioma do mundo (Parton et al., 1987; Paustian et al., 1992; Metherell et al., 1994), especialmente em ecossistemas de clima temperado.

Estudos têm sido conduzidos utilizando-se do modelo Century para melhorar as estimativas em solos de regiões tropicais e subtropicais, com o intuito de determinar a magnitude e os coeficientes de conversão entre os compartimentos da MOS (Parfitt et al., 1997). No Brasil, o Century já foi testado por diversos autores tanto em regiões tropicais (Silva \& Pasqual, 1999; Cerri et al., 2003) como em subtropicais (Silveira et al., 2000; Leite et al., 2004; Lopes et al., 2008; Bortolon et al., 2009; Tornquist et al., 2009); Lopes et al. (2008) e Tornquist et al. (2009) obtiveram sucesso aplicando a modelagem dinâmica espacialmente explícita associando o Century e SIG.

Conceitualmente, existem dois métodos extremos para a integração espaço-temporal de modelos dinâmicos com SIG, denominados de acoplamento livre e acoplamento ajustado, respectivamente. $\mathrm{O}$ acoplamento livre mantém a base de dados geoespaciais (BDGE) separada estruturalmente do modelo dinâmico. As simulações são executadas em software específico do modelo dinâmico, e os dados gerados são extraídos manualmente ou por um aplicativo de extração (interface) e posteriormente inseridos na BDGE, que será gerenciada em um SIG. $\mathrm{O}$ acoplamento ajustado integra completamente o modelo dinâmico e a BDGE em um ambiente SIG. A BDGE é gerenciada (adição, edição, deleção de dados analíticos) e as simulações são executadas no SIG usando a mesma plataforma ou interface (Nørgaard, 2004).

Assim, este trabalho objetivou utilizar o modelo Century associado a técnicas de geoprocessamento e sensoriamento remoto para avaliar os efeitos das alterações do uso agrícola e manejo do solo nos estoques de COS em propriedades rurais do Distrito Santana, Ijuí - RS.

\section{MATERIAL E MÉTODOS}

\section{Descrição da área de estudo}

Este estudo foi realizado no Distrito Santana, município de Ijuí, na região das Missões do Rio Grande do Sul (28 $20^{\prime} \mathrm{S}$ e $53^{\circ} 53^{\prime} \mathrm{W}$, entre 220 e $400 \mathrm{~m}$ de altitude) (Figura 1). A área é delimitada ao norte e ao sul, respectivamente, pelos rios Ijuí e Potiribu; ao oeste, pela confluência desses rios; e ao leste, pelo limite atual entre os municípios de Ijuí e Bozano, abrangendo um total de 10.669 ha ocupados por aproximadamente 400 pequenas propriedades 
com 25 ha. De acordo com levantamento de solos realizado por Abrão \& Azolin (1970) na escala 1:50.000, cuja classificação dos solos foi atualizada conforme Embrapa (2006), no Distrito Santana ocorrem Latossolo Vermelho distroférrico (6.359 ha, $60 \%$ ), Neossolo Regolítico eutrófico (1.833 ha, $17 \%$ ), Chernossolo Argilúvico órtico (1.468 ha, 14\%) e Neossolo Flúvico (1.009 ha, 9 \%), distribuídos conforme figura $2 \mathrm{a}$.

A região foi escolhida com base na disponibilidade de mapa de levantamento de solos, dados históricos do uso agrícola, presença de vegetação original e de lavouras com tempo de uso agrícola distinto. Assim, para fins de amostragem e detalhamento do histórico de uso e manejo dos solos, foram identificadas, dentro do Distrito Santana, quatro áreas (Figura 1) homogêneas em termos de sistemas de culturas, sistemas de manejo do solo adotados e vegetação nativa, mas que tenham sido convertidas para agricultura em diferentes épocas. As quatro áreas foram identificadas como área 1 (51,1 ha), área 2 (142,0 ha), área 3 (77,1 ha) e área 4 (102,2 ha). Dentro dessas áreas foram amostradas somente matas nativas e lavouras localizadas sob Latossolo de topo (declive $<8 \%$ ), onde o solo é mais intensamente cultivado e bastante representativo da agricultura adotada no Distrito Santana.

\section{Amostragem do solo}

A amostragem do solo procurou caracterizar os estoque de COS e o histórico de uso e manejo do solo nas áreas de estudo. Para isso, inicialmente foram reconstituídas no tempo - com base em relatos históricos (1900-1955), fotos aéreas (1956, 1964 e 1975) e imagens de satélite (1987 e 2007) - as alterações no uso e manejo do solo na região em estudo, estabelecendo-se diferentes períodos de conversão de mata nativa em lavouras. Desse modo, foi possível identificar lavouras iniciadas entre 1901 e 1930, entre 1931 e 1956, entre 1957 e 1964, entre 1965 e 1975, entre 1976 e 1987 e entre 1988 e 2007.

Posteriormente, foram coletadas amostras nas quatro áreas (Figura 1), sendo sete pontos na área 1 [mata (2 pontos) e lavouras iniciadas entre $1901 \mathrm{e}$ 1930 ( 2 pontos), 1931 e 1956 (1 ponto) e 1976 e 1987 ( 2 pontos)]; quatro pontos na área 2 [mata (1 ponto) e lavouras iniciadas entre 1931 e 1956 (1 ponto), 1965 e 1975 ( 1 ponto) e 1976 e 1987 (1 ponto)]; cinco pontos na área 3 [mata (1 ponto) e lavouras iniciadas

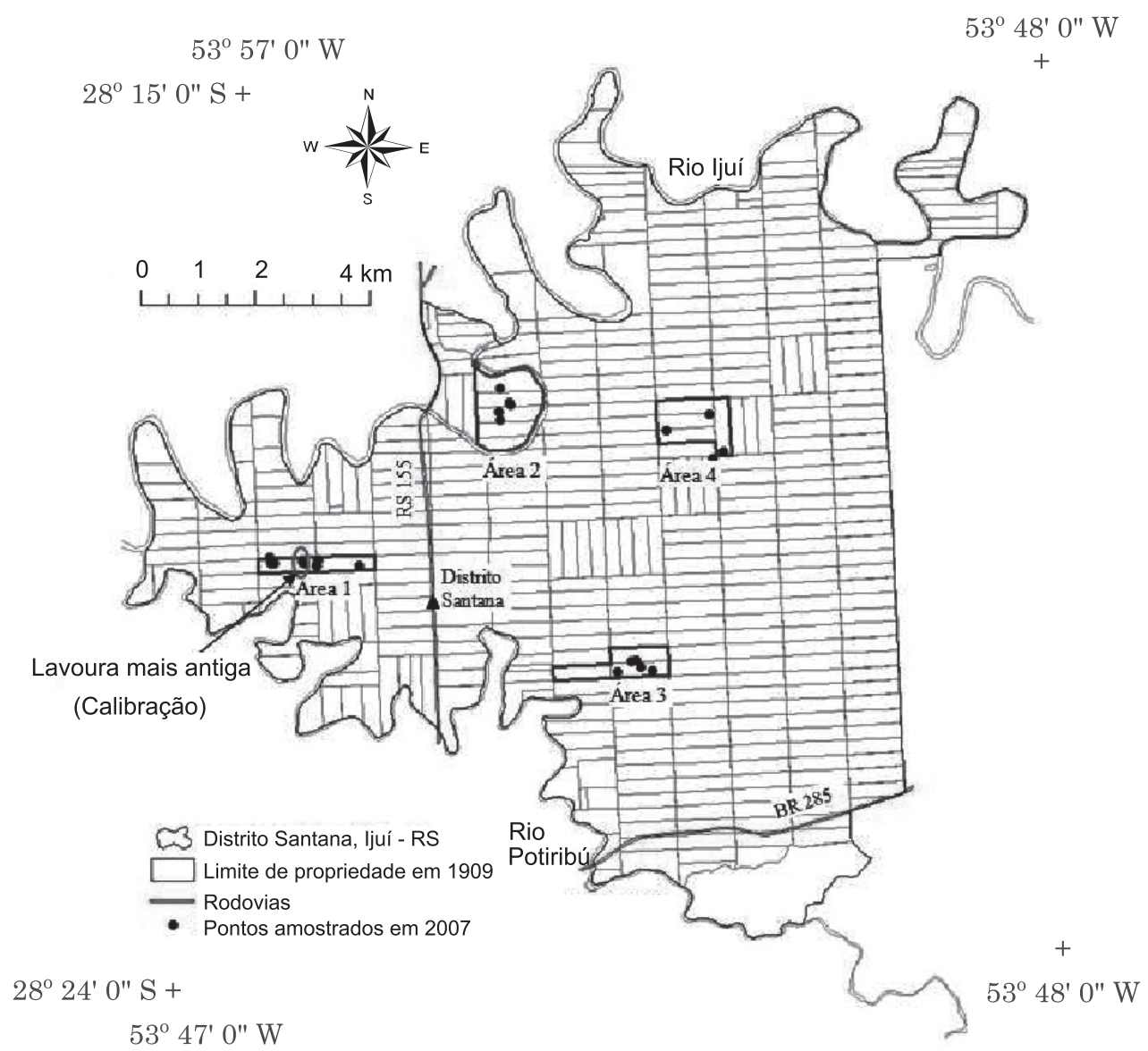

Figura 1. Localização do Distrito Santana, Ijuí - RS, e a distribuição espacial dos pontos amostrados em quatro áreas homogêneas. 


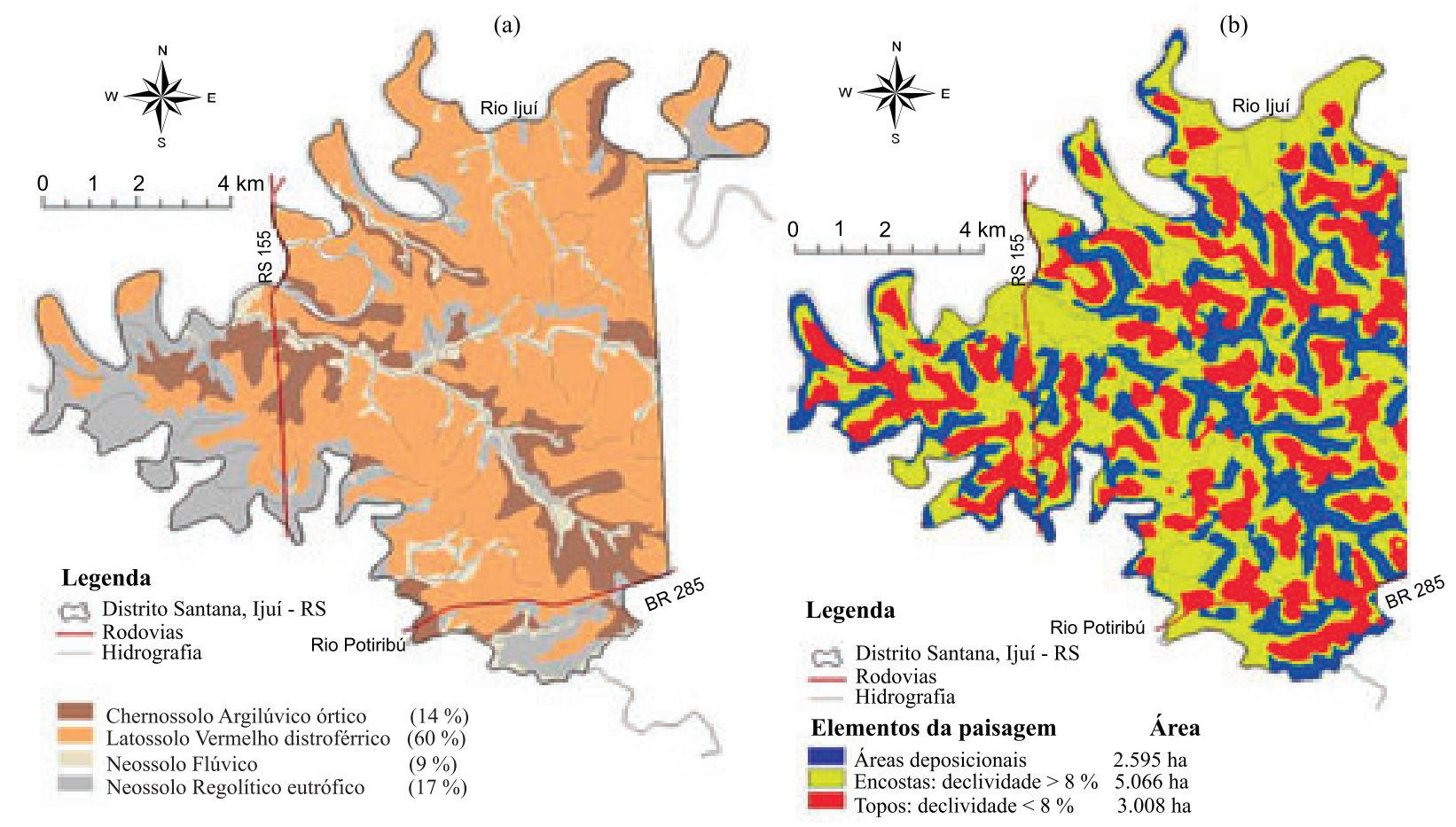

Figura 2. (a) Mapa de solos compilado de Abrão \& Azolin (1970) e (b) mapa da distribuição dos elementos da paisagem do Distrito Santana, Ijuí - RS.

entre 1901 e 1930 (1 ponto), 1931 e 1956 (1 ponto), 1965 e 1975 ( 1 ponto) e 1976 e 1987 ( 1 ponto)]; e quatro pontos na área 4 [mata ( 2 pontos) e lavouras iniciadas entre 1931 e 1956 ( 2 pontos)], totalizando 20 pontos amostrados com duas repetições por ponto (com exceção das lavouras da área 2 , onde tem-se uma repetição por ponto), nas camadas de 0 a 10 e de 10 a $20 \mathrm{~cm}$, todos situados sob Latossolo com declividade menor que $8 \%$ (topo).

Foram determinados a densidade do solo, pelo método do anel volumétrico $(8,5 \mathrm{~cm} \varnothing \times 5 \mathrm{~cm})$ descrito em Blake \& Hartge (1986), os teores de C orgânico total, por combustão seca (Nelson \& Sommers, 1996) em analisador CH Shimadzu, e a granulometria do solo (Embrapa, 1997), que são informações necessárias para a parametrização inicial (inicialização) do modelo Century. Os estoques de COS foram calculados em massa de solo equivalente à camada de 0 a $20 \mathrm{~cm}$ sob vegetação nativa de cada uma das quatro áreas e das quatro classes de solo, com base no método descrito por Ellert \& Bettany (1995), usando essa massa de solo sob vegetação nativa para recalcular os estoques de COS nas áreas sob cultivo.

\section{Histórico de uso e manejo do solo}

A ocupação dos solos da região que engloba o Distrito Santana, originalmente coberta por Floresta Ombrófila Mista, ocorreu a partir de 1900, com a chegada dos primeiros imigrantes europeus a Ijuí. A exploração agrícola caracterizou-se por uso da mão de obra familiar e utilização de práticas agrícolas nos moldes europeus (Brum, 1983; Siekierski \& Lazzarotto, 1987; Rückert, 2003). Inicialmente, houve um período de agricultura colonial (entre 1900 e 1970), com preparo de solo predominantemente com tração animal, criação de animais e cultivo de milho, trigo, feijão, lentilha, mandioca e soja (a partir de 1956), entre outras espécies, para subsistência, sendo o cultivo baseado na fertilidade natural do solo. Na década de 1970, teve início o período de agricultura mecanizada, com preparo do solo com aração e gradagem e intensa mobilização deste (preparo convencional, PC), uso de fertilizantes e corretivos químicos, sucessão de cultivos de trigo e soja, além da queima da palha do trigo, causando degradação física do solo. A partir de 1987, foram adotadas práticas conservacionistas de manejo do solo, com preparo com escarificador e grade (preparo reduzido, PR), com a palha do trigo deixando de ser queimada e a cultura da aveia passando a dividir espaço com o trigo. Em 1995 teve início o sistema plantio direto (PD), que vem sendo mantido até os dias atuais. Na área há lavouras que foram submetidas ao uso agrícola em épocas diferentes, pelo avanço do desmatamento, para atender às necessidades dos produtores, mas que atualmente encontram-se submetidas a condições de uso e manejo dos solos semelhantes entre si. 


\section{Unidades de simulação (US)}

Para executar uma modelagem espacialmente explícita da dinâmica do COS similar à realizada por Nørgaard (2004), buscou-se definir diferentes unidades de simulação (US), que são zonas similares quanto à classe de solo (Chernossolo, Latossolo, Neossolo Flúvico e Neossolo Regolítico, figura 2a), elementos da paisagem (topo, encosta e áreas deposicionais - figura $2 \mathrm{~b}$ ) e tempo de uso agrícola dos solos (1901, 1957, 1965, 1976 e 1988). Para delimitação das US, utilizaram-se técnicas de geoprocessamento realizadas em ambiente ArcGIS 9.x (ESRI, 2003).

Com esse objetivo, a identificação espacializada da evolução de uso das terras no Distrito Santana para os anos de 1956, 1964 e 1975 foi feita a partir de registros aerofotogramétricos disponíveis nas escalas 1:30.000, 1:60.000 e 1:110.000, respectivamente. As aerofotos que cobriam a região em estudo foram digitalizadas em scanner de mesa e georreferenciadas à carta topográfica em escala 1:50.000 correspondente à região de interesse: Folha Ijuí (Brasil, 1980), associada ao datum Córrego Alegre. A partir da identificação visual das feições da vegetação por fotointerpretação, construiu-se um mapa vetorial com polígonos representando o uso das terras (genericamente tratado como conversão para agricultura a partir do desmatamento) em 1956, 1964 e 1975. Para os anos de 1987 e 2007, a identificação espacializada das mudanças de uso do solo foi feita a partir da classificação por fotointerpretação da imagem do satélite LANDSATTM5 de 14 de março de 1987, com resolução espacial de $30 \mathrm{~m}$, e da imagem ALOS-PRISM de 19 de abril de 2007, com resolução espacial de $2,85 \mathrm{~m}$. O mapa de evolução de uso das terras foi obtido pelo cruzamento dos planos de informação gerados para cada data, tendo-se assim individualizadas em um único mapa as lavouras iniciadas entre 1901 e 1956, entre 1957 e 1964, entre 1965 e 1975, entre 1976 e 1987 e entre 1988 e 2007.

Durante o processo de vetorização e individualização dos polígonos referentes aos remanescentes da vegetação original em cada data avaliada (1956, 1964, 1975, 1987 e 2007), foi tomada como referência a imagem ALOS-PRISM, por ser de alta resolução $(2,85 \mathrm{~m})$ e a mais recente disponível, associada ao mapa de distribuição dos lotes no Distrito Santana (digitalizado e georreferenciado ao mapa-base), datado de 1909 (Figura 1), em relação às aerofotos datadas de 1956. Esse procedimento foi adotado para minimizar os erros de posicionamento geográfico devido ao georreferenciamento das aerofotos, já que a imagem ALOS-PRISM possui menor erro associado ao georreferenciamento. Os limites dos lotes auxiliaram na localização dos remanescentes de mata nativa nas diferentes datas, visto que as divisas de propriedades, na sua maioria, atualmente seguem os mesmos limites estabelecidos em 1909. Para delimitação espacial da vegetação original nas datas intermediárias (1964, 1975 e 1987), tomou-se como base o mapa vetorial da vegetação de 1956, somente reduzindo-se os polígonos quando as aerofotos e a imagem evidenciaram a remoção da mata. Assim, não foram consideradas áreas em que a vegetação nativa se regenerou após $1956 \mathrm{ou}$ em que houve o reflorestamento. Quando ocorreu aumento da área vegetada por mata, os polígonos foram mantidos com tamanho igual ao da data anterior. Além disso, áreas sob vegetação nativa que ocupavam menos de 0,25 ha foram desconsideradas em todas as datas.

Para individualização dos elementos da paisagem, foi produzido um modelo numérico do terreno em formato raster com resolução espacial de $20 \mathrm{~m}$, obtido pela interpolação das curvas de nível espaçadas verticalmente de $20 \mathrm{~m}$ e pontos cotados que constam na base cartográfica utilizada neste estudo. A partir do modelo numérico do terreno, foi gerado um plano temático de declividade, e ambos foram necessários para que a superfície fosse classificada quanto aos elementos da paisagem: topos, encostas e áreas deposicionais, conforme sugerido por Tornquist et al. (2009). Para isso, foi usado o algoritmo TPI (Topographic Position Index), utilizado como uma extensão do ArcView 3.2 (Jenness, 2008). Foi utilizado o padrão circular (circle) de busca nas vizinhanças, com raio de $600 \mathrm{~m}$, adotando-se os seguintes critérios: a) topos: pixels com declividade entre 0 e $<8 \%$; b) encostas: pixels com declividade $>$ $8 \%$; e c) áreas deposicionais: pixels com declividade = zero, que não sejam topos (Figura $2 \mathrm{~b}$ ).

Finalmente, um plano temático vetorial com polígonos representando espacialmente as diferentes US foi obtido pelo cruzamento entre os planos de informação vetoriais de solos, elementos da paisagem e tempo de uso agrícola do solo (fatorial $4 \times 3 \times 5$ ). Do resultado deste fatorial (60 US) foram excluídas as US inexistentes (10 US), visto que o Neossolo Flúvico somente ocorre em condições deposicionais na paisagem. Às 50 US restantes foram acrescentadas mais quatro, referentes à vegetação original correspondente a cada tipo de solo, totalizando 54 US.

\section{Inicialização do modelo}

O modelo Century 4.0 (Metherel et al., 1994) foi inicializado para cada uma das quatro áreas homogêneas amostradas em 2007 dentro do Distrito Santana e para cada uma das classes de solo mapeadas na região com os respectivos dados locais de solo (Quadros 1 e 2, respectivamente). No quadro 2 , 
os dados para o Latossolo foram obtidos a partir da média daqueles apresentados no quadro 1 , ao passo que para o Neossolo Regolítico, o Chernossolo e o Neossolo Flúvico os dados de granulometria foram obtidos pela média dos dados apresentados por Abrão \& Azolin (1970) dentro de cada classe de solo, a densidade do solo foi estimada conforme sugerido por Benites et al. (2007) e o estoque de COS original foi calculado com base em dados apresentados por Abrão \& Azolin (1970), correspondendo a um ponto dentro de cada classe de solo.

Os dados climáticos utilizados na inicialização do Century foram obtidos da Estação Meteorológica de Ijuí, onde foi observada precipitação pluvial média anual de $1.720 \mathrm{~mm}$, temperatura mínima média anual de $13,9^{\circ} \mathrm{C}$ e temperatura máxima média anual de $25,9^{\circ} \mathrm{C}$. Essa região é classificada como Cfa na classificação climática de Köppen-Geiger.

\section{Cenários históricos de manejo de solo}

Os cenários de manejo do solo utilizados nas simulações constam no quadro 4 e foram reconstituídos com base no histórico de uso e manejo realizado na área, conforme descrito anteriormente. Para o período colonial, foram utilizadas nas simulações somente as culturas principais (milho, trigo e soja) cultivadas na época, bem como os períodos de pousio adotados pelos agricultores da região. Isso porque não há, até o momento, estudos que visem à obtenção dos parâmetros exigidos pelo Century para toda a diversidade de culturas utilizadas na época, não sendo possível, portanto, incluí-las nas simulações.

\section{Calibração e validação do modelo}

A calibração é fundamental em estudos de modelagem, pois visa estabelecer coincidências entre dados medidos (observados no campo) e os dados estimados pelo modelo por meio de ajustes de parâmetros internos deste (Gomes \& Varriale, 2004). Já na etapa de validação de um modelo, as suas estimativas devem ser comparadas com dados observados diversos daqueles usados na sua construção e calibração (Leal, 1996; Gomes \& Varriale, 2004).

Em geral, o processo de calibração do Century é realizado de forma interativa com a execução do

Quadro 1. Composição granulométrica, densidade do solo e estoque de carbono orgânico do solo (COS) em condição de mata nativa nas quatro áreas amostradas, no Distrito Santana, Ijuí-RS, sob Latossolo de topo, equivalentes à camada de 0 a $20 \mathrm{~cm}$, utilizados na inicialização do modelo Century, na etapa de calibração principal

\begin{tabular}{|c|c|c|c|c|c|}
\hline \multirow{2}{*}{ Área } & \multicolumn{3}{|c|}{ Granulometria $^{(1)}$} & \multirow{2}{*}{ Densidade do solo } & \multirow{2}{*}{ Estoque de COS } \\
\hline & Areia & Silte & Argila & & \\
\hline & 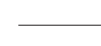 & $\mathrm{g} \mathrm{kg}^{-1}$ & - & $\mathrm{g} \mathrm{cm}^{-3}$ & $\mathrm{Mg} \mathrm{ha}^{-1}$ \\
\hline 1 & 135 & 277 & 588 & 0.90 & 52.5 \\
\hline 2 & 176 & 191 & 633 & 0.81 & 43.7 \\
\hline 3 & 96 & 101 & 803 & 0.92 & 57.9 \\
\hline 4 & 103 & 234 & 663 & 0.79 & 43.3 \\
\hline
\end{tabular}

(1) Média dos pontos amostrados dentro de cada área (mata e lavoura), Bortolon et al. (2011).

Quadro 2. Composição granulométrica, densidade do solo e estoque de carbono orgânico do solo (COS) em condição de mata nativa nas diferentes classes de solo, no Distrito Santana, Ijuí-RS, equivalentes à camada de 0 a $20 \mathrm{~cm}$, utilizados na inicialização do modelo Century, na etapa de calibração para generalizações

\begin{tabular}{|c|c|c|c|c|c|}
\hline \multirow{2}{*}{ Classe de solo } & \multicolumn{3}{|c|}{ Granulometria } & \multirow{2}{*}{ Densidade do solo } & \multirow{2}{*}{ Estoque de COS } \\
\hline & Areia & Silte & Argila & & \\
\hline & & $\mathrm{g} \mathrm{kg}^{-1}$ & - & $\mathrm{g} \mathrm{cm}^{-3}$ & $\mathrm{Mg} \mathrm{ha}^{-1}$ \\
\hline Latossolo $^{(1)}$ & 128 & 200 & 672 & 0,86 & 49,4 \\
\hline Chernossolo ${ }^{(2)}$ & 194 & 152 & 654 & 1,17 & 49,4 \\
\hline Neossolo Regolítico ${ }^{(2)}$ & 510 & 157 & 333 & 1,23 & 63,2 \\
\hline Neossolo Flúvico ${ }^{(2)}$ & 255 & 220 & 525 & 1,19 & 47,9 \\
\hline
\end{tabular}

(1) Média dos pontos amostrados em 2007, apresentados no quadro 1. (2) A granulometria foi obtida pela média dos dados apresentados por Abrão \& Azolin (1970) dentro de cada classe de solo; a densidade do solo foi estimada conforme sugerido por Benites et al. (2007); o estoque de COS original foi calculado com base em dados apresentados por Abrão \& Azolin (1970), correspondendo a um ponto dentro de cada classe de solo. 
modelo, inspeção das saídas e alteração da máxima produção bruta mensal de biomassa da floresta e,ou, das culturas, até que o SOMTC (estoque de COS simulado) aproxime-se ao máximo do estoque de COS medido. Neste estudo, o Century foi calibrado em duas etapas: a primeira foi tratada como "calibração principal", e a segunda, como "calibração para generalização".

\section{Calibração principal}

Nesta etapa, o modelo Century foi ajustado para que houvesse coincidência entre os valores de COS estimados e os medidos sob a vegetação nativa e lavouras das áreas 1, 2, 3 e 4 (Figura 1) localizadas sob Latossolo de topo e que foram sumetidas a amostragem detalhada em 2007 (Bortolon et al., 2011).

Calibração das florestas - inicialmente, o modelo foi executado por um período de 3.000 anos sob a condição original de floresta subtropical (execução de equilíbrio), criada a partir da opção do default "Luquilo - floresta tropical", para cada área (áreas 1, 2, 3 e 4) a fim de estabilizar as variáveis de saída. Ao final dessas simulações, os estoques de COS medidos e simulados na camada de 0 a $20 \mathrm{~cm}$ foram comparados entre si para cada área. Como a adição de $\mathrm{C}$ ao solo pela floresta é desconhecida e assumiu-se que os estoques de COS são estáveis sob condição nativa, foi ajustado o parâmetro referente à máxima produção bruta mensal de biomassa pela floresta $(\mathrm{PRDX}(2))$ nas quatro áreas amostradas, para coincidir com o COS medido na respectiva floresta (área $1=52,5 \mathrm{Mg} \mathrm{ha}^{-1}$, área $2=43,7 \mathrm{Mg} \mathrm{ha}^{-1}$, área $3=57,9 \mathrm{Mg} \mathrm{ha}^{-1}$ e área $\left.4=43,3 \mathrm{Mg} \mathrm{ha}^{-1}\right)$. Além disso, estudos anteriores utilizando o modelo Century no Rio Grande do Sul evidenciaram baixas relações $\mathrm{C} / \mathrm{N}$ ao longo das simulações, exigindo ajustes em parâmetros relacionados com a relação $\mathrm{C} / \mathrm{N}$ dos compartimentos de $\mathrm{C}$ e perdas de $\mathrm{N}$ mineralizado (Bortolon et al., 2009). Assim, o modelo foi ajustado conforme sugerido, e os parâmetros estão listados no quadro 3.

Calibração para condições de cultivo - para a execução desta etapa, foi selecionada a lavoura mais antiga identificada no Distrito Santana. Esta lavoura está localizada na área 1 e foi convertida para agricultura no período de 1901 a 1930 (Figura 1). A calibração para condições de cultivo foi baseada em dados apresentados por Debarba (2002), que estimou a adição de $\mathrm{C}$ ao solo pelas culturas de trigo, milho e soja usando dados de campo e índices de colheita dessas culturas para o período de 1950 a 1995, para os municípios de Ijuí e Santa Rosa (aproximadamente $80 \mathrm{~km}$ da área de estudo). Esses cálculos resultaram em 0,71,
1,20 e $1,08 \mathrm{Mg} \mathrm{ha}^{-1}$ of $\mathrm{C}$ adicionados anualmente pela biomassa da parte aérea de trigo, milho e soja, respectivamente. Para atingir esses valores, foi ajustado o parâmetro referente ao potencial mensal de produção de biomassa pela parte aérea de cada cultura (PRDX(1)). Além disso, foi usado um "efeito adicional de cultivo" por dois meses seguidos após as operações de preparo do solo no período de PC (1971 a 1986), como sugerido por Leite et al. (2004) e Bortolon et al. (2009), estendendo-se assim o efeito do preparo sobre a decomposição da matéria orgânica do solo. Também foi ajustado o efeito do tipo de preparo do solo na decomposição do compartimento de $\mathrm{C}$ orgânico lento, pelo ajuste do parâmetro de cultivo, CLTEFF(2) (Quadro 3), que atua como multiplicador para aumentar a decomposição desse compartimento de $\mathrm{C}$ no mês do cultivo (Bortolon et al., 2009).

\section{Calibração para generalização}

Para que as simulações dos estoques de COS pelo modelo Century obtidas nas condições do Latossolo fossem estendidas para as demais classes de solos encontradas no Distrito Santana (Figura 2a), algumas generalizações foram necessárias. Para isso, foram criadas quatro opções de "floresta subtropical" para representar a mata nativa de cada classe de solo simulada a partir da opção de floresta tropical gerada na etapa de calibração principal, mantendo-se os ajustes já realizados naquela etapa (calibração para florestas e condições de cultivo). Posteriormente, o modelo foi inicializado para cada uma das quatro classes de solo, com os dados locais de clima da região e de solo correspondentes a cada classe listados no quadro 2 . Os parâmetros PRDX(2) (máxima produção bruta mensal de biomassa pela floresta) de cada mata nativa (Quadro 3) foram ajustados para que a variável de saída SOMTC se estabilizasse, após o modelo ser executado por 3.000 anos (execução de equilíbrio), coincidindo com os estoques de COS medidos no solo sob vegetação nativa respectiva de cada classe de solo; a média dos estoques de COS medidos nas matas das áreas 1 , 2, 3 e 4 representou o estoque medido no Latossolo, e os dados apresentados por Abrão \& Azolin (1970) dentro de cada classe de solo foram utilizados para representar os estoques de COS medidos nas matas do Neossolo Regolítico, do Chernossolo e do Neossolo Flúvico (Quadro 2). Após o PRDX(2) das matas ter sido ajustado para cada classe de solo na execução de equilíbrio, procedeu-se às simulações correspondentes às 54 US nas condições de solos cultivados com os cenários de manejo históricos (de 1901 até 2007).

A validação do modelo Century baseou-se em dados observados em 10 lavouras iniciadas em 
diferentes épocas, amostradas em 2007 na camada de 0 a $20 \mathrm{~cm}$ de Latossolo de topo, no Distrito Santana, Ijuí (RS), nas áreas 1, 2, 3 e 4 (Figura 1), exceto a lavoura utilizada na etapa de calibração principal. A acurácia das simulações, após os ajustes realizados na calibração principal em relação aos dados observados, foi testada com base no coeficiente de correlação de Pearson (r), na raiz quadrada de erro do modelo (RMSE - Root mean square error of model) e na eficiência da modelagem (ME) a partir de análise estatística proposta por Smith et al. (1997).

Durante o processo de calibração e validação do modelo Century, obedeceu-se à sequência: calibração principal - validação - calibração para generalizações. As etapas de calibração principal e de validação do modelo Century foram abordadas detalhadamente em Bortolon et al. (2011).

\section{Generalização das estimativas do modelo}

Após o modelo Century ter sido calibrado (calibração principal) e validado com base em estoques de COS medidos em mata nativa e lavouras amostradas nas áreas 1, 2, 3 e 4 (Figura 1) sob Latossolo de topo, assumiu-se que o modelo apresentaria o mesmo desempenho nas demais classes de solo (Chernossolo, Neossolo Flúvico e Neossolo Regolítico) e posições na paisagem (encosta e superfícies deposicionais) do Distrito Santana, partindo-se para a etapa de generalização das estimativas do modelo.

Nesta etapa, o modelo já calibrado para cada uma das quatro classes de solos encontradas na área de estudo (Latossolo, Chernossolo, Neossolo Flúvico e Neossolo Regolítico), foi executado para as 54 US do Distrito Santana nas condições de solos cultivados com os cenários de manejo históricos (de 1901 até 2007) listados no quadro 4. Pelo fato de as informações espacializadas disponíveis sobre a evolução de uso dos solos do Distrito Santana datarem de 1956 (a mais antiga disponível), não foi possível estabelecer um período intermediário de início do uso agrícola dos solos entre 1901 e 1956.

As diferenças entre os elementos da paisagem, topo, encosta e superfície deposicional referem-se

\section{Quadro 3. Parâmetros do modelo Century 4.0 ajustados para as simulações e os valores originais}

\begin{tabular}{|c|c|c|}
\hline Parâmetro & Original & Modificado \\
\hline \multicolumn{3}{|l|}{ Parâmetros fixos- FIX.100 } \\
\hline $\begin{array}{l}\text { VARAT2(1.1) - C/N máxima do material que entra no compartimento lento } \\
\text { VARAT3(1.1) - C/N máxima do material que entra no compartimento passivo } \\
\text { VLOSSG - Fração mensal do total de } \mathrm{N} \text { mineralizado que é volatilizada }\end{array}$ & $\begin{array}{l}20 \\
8 \\
0,01\end{array}$ & $\begin{array}{l}25 \\
14 \\
0,03\end{array}$ \\
\hline \multicolumn{3}{|l|}{ Parâmetros de floresta-TREE.100 } \\
\hline $\begin{array}{l}\text { PRDX(2) - Produção potencial de biomassa pela floresta }\left(\mathrm{g} \mathrm{C} \mathrm{m}^{-2} \mathrm{month}^{-1}\right) \\
\text { Floresta subtropical-Latossolo Área 1- PRTP } \\
\text { Floresta subtropical-Latossolo Área 2- PRTP } \\
\text { Floresta subtropical-Latossolo Área 3- PRTP } \\
\text { Floresta subtropical-Latossolo Área 4- PRTP } \\
\text { Floresta subtropical-Latossolo - PRTP } \\
\text { Floresta subtropical-Chernossolo - PRTP } \\
\text { Floresta subtropical-Neossolo Flúvico - PRTP } \\
\text { Floresta subtropical-Neossolo Regolítico - PRTP }\end{array}$ & $\begin{array}{l}800 \\
800 \\
800 \\
800 \\
800 \\
800 \\
800 \\
800\end{array}$ & $\begin{array}{r}881 \\
732 \\
842 \\
680 \\
790 \\
833 \\
900 \\
1550\end{array}$ \\
\hline \multicolumn{3}{|l|}{ Parâmetros de culturas-CROP.100 } \\
\hline $\begin{array}{l}\text { PRDX(1) - Produção potencial de biomassa pela parte aéras das culturas (g C } \\
\text { Milho - C1 } \\
\text { Trigo - W0 } \\
\text { Trigo - W1 } \\
\text { Trigo - W2 } \\
\text { Aveia-preta - OAT1 } \\
\text { Aveia-preta - OAT2 } \\
\text { Soja- SYBN1 } \\
\text { Soja - SYBN2 } \\
\text { Soja - SYBN3 } \\
\text { Soja - SYBN4 } \\
\text { Pousio - WEEDS }\end{array}$ & $\begin{array}{l}250 \\
150 \\
250 \\
300 \\
220 \\
320 \\
300 \\
300 \\
300 \\
450 \\
300\end{array}$ & $\begin{array}{l}200 \\
100 \\
115 \\
110 \\
185 \\
175 \\
130 \\
210 \\
175 \\
200 \\
150\end{array}$ \\
\hline \multicolumn{3}{|l|}{ Parâmetros de cultivo - CULT.100 } \\
\hline $\begin{array}{l}\text { CLTEFF(2) - Fator de cultivo para decomposição do compartimento lento } \\
\text { Preparo convencional - CVTIL } \\
\text { Plantio direto - NTIL }\end{array}$ & $\begin{array}{l}1,60 \\
1,00\end{array}$ & $\begin{array}{l}1,80 \\
1,10\end{array}$ \\
\hline
\end{tabular}




\section{Quadro 4. Cenários de manejo utilizados nas simulações com o modelo Century (1901 a 2007), no Distrito Santana, Ijuí-RS}

\begin{tabular}{|c|c|c|}
\hline \multicolumn{2}{|c|}{ Cenário (período) } & Descrição \\
\hline I & $\begin{array}{c}\text { Colonial } 1 \\
(1901-1955)\end{array}$ & 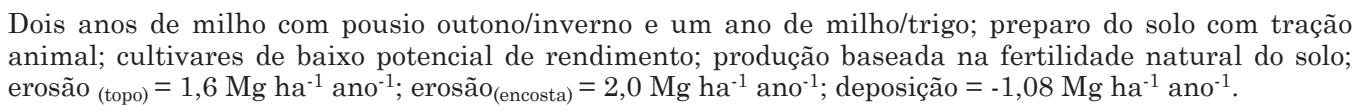 \\
\hline II & $\begin{array}{c}\text { Colonial } 2 \\
(1956-1970)\end{array}$ & $\begin{array}{l}\text { Dois anos de milho com pousio outono/inverno e um ano de soja/trigo; preparo do solo com tração animal; } \\
\text { cultivares de baixo potencial de rendimento; produção baseada na fertilidade natural do solo; erosão (topo) }= \\
3,0 \mathrm{Mg} \mathrm{ha}^{-1} \mathrm{ano}^{-1} \text {; erosão (encosta) }=4,0 \mathrm{Mg} \mathrm{ha}^{-1} \text { ano }^{-1} \text {; deposição }=-2,20 \mathrm{Mg} \mathrm{ha}^{-1} \text { ano }^{-1} \text {. }\end{array}$ \\
\hline III & $\begin{array}{l}\text { Preparo } \\
\text { convencional } \\
(1971-1986)\end{array}$ & 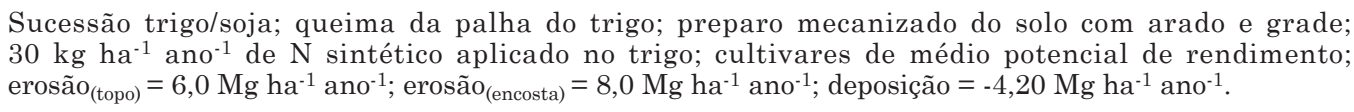 \\
\hline IV & $\begin{array}{l}\text { Preparo reduzido } \\
\quad(1987-1994)\end{array}$ & 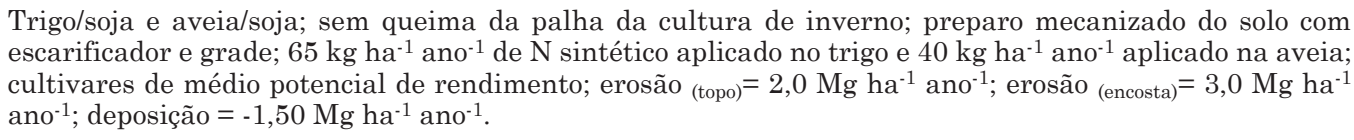 \\
\hline $\mathrm{V}$ & $\begin{array}{l}\text { Plantio direto } \\
\text { "atual" } \\
(1995-2007)\end{array}$ & $\begin{array}{l}\text { Trigo/soja e aveia/soja; sem queima da palha da cultura de inverno; dessecação da aveia; plantio direto; } \\
65 \mathrm{~kg} \mathrm{ha}^{-1} \mathrm{ano}^{-1} \mathrm{de} \mathrm{N} \text { sintético aplicado no trigo e } 40 \mathrm{~kg} \mathrm{ha}^{-1} \text { ano }^{-1} \text { aplicado na aveia; cultivares de alto } \\
\text { potencial de rendimento; erosão } \\
-0,48 \mathrm{Mg} \mathrm{ha}_{\text {(topo }}=0,6 \mathrm{Mg} \mathrm{ha}^{-1} \mathrm{ano}^{-1} \text {; } \text { erosão }_{(\text {encosta) }}=1,0 \mathrm{Mg} \mathrm{ha}^{-1} \text { ano }^{-1} \text {; deposição }= \\
\end{array}$ \\
\hline
\end{tabular}

unicamente à variação das taxas de erosão (topos e encostas) e deposição (superfície deposicional). No entanto, dentro de cada elemento da paisagem as taxas de erosão e deposição diferem quanto ao cenário de manejo adotado (Quadro 4), mas não variam entre as classes de solo. Além disso, considerou-se que, do total de sedimentos depositados nas superfícies deposicionais, $30 \%$ efetivamente permaneceram nessas áreas, sendo utilizado um fator de enriquecimento (ENRICH) igual a 1,0, conforme proposto por Pennock \& Frick (2001), enquanto nos topos e encostas esse fator foi mantido padrão (igual a 2,0 ).

No Century, a quantidade de COS perdido por erosão é calculada multiplicando-se a quantidade de COS da camada simulada (0 a $20 \mathrm{~cm}$ ) pelo fator de enriquecimento. Assim, adotar valor 1,0 para o fator de enriquecimento significa dizer que a quantidade de $\operatorname{COS}$ no sedimento é igual à do solo que o gerou. Também foram utilizadas taxas de erosão negativas nas áreas deposicionais para contornar a limitação do Century em simular essa situação. Esse procedimento foi adotado com sucesso por Pennock \& Frick (2001) e Tornquist et al. (2009). Por isso, a deposição considerada no presente estudo não resulta da modelagem do transporte e acúmulo de sedimentos de áreas adjacentes erodidas, sendo um artifício adotado para que fosse possível estimar, ainda que de forma simplificada, a redistribuição do $\mathrm{C}$ na paisagem, considerando o processo deposicional e não somente a erosão, como prevê a versão 4.0 do modelo Century.

As simulações pelo modelo Century foram operacionalizadas com o auxílio da interface
i-Century ou Interactive Century (CARD, 2008), conforme realizado por Nørgaard (2004) e Tornquist et al. (2009). Esse software armazena as variáveis e parâmetros do modelo em um banco de dados MS Access ${ }^{\circledR}$, permitindo a fácil manipulação de dados, a execução do modelo e a interação com sistemas de geoprocessamento, sem diferir em qualquer aspecto de uma aplicação tradicional do Century.

Após o Century ter sido executado para todas as US, os dados de interesse no presente estudo referentes às variáveis de saída SOMTC (COS simulado) e SCLOSA (C perdido ou acumulado anualmente associado com o solo devido aos processos de erosão e deposição, respectivamente) foram extraídos, organizados e sintetizados de modo que fossem obtidas estimativas referentes aos anos de 1955, 1970, 1986, 1994 e 2007, que correspondem ao último ano de adoção de cada cenário de manejo em estudo, e ao ano de 1900, que representou a condição original do solo. Esses dados foram inseridos manualmente na tabela de atributos associada ao plano vetorial de US no SIG, passando então a fazer parte da BDGE, configurando o acoplamento livre entre o SIG e as estimativas do Century, descrito por Nørgaard (2004).

\section{RESULTADOS E DISCUSSÃO}

\section{Evolução do uso agrícola do solo}

A distribuição espacial da evolução do uso agrícola do solo (Figura 3) evidencia a redução 
drástica da cobertura vegetal original (mata) desde o início da colonização (1900) até os dias atuais (2007).

Entre os diferentes intervalos de tempo em estudo, foi no período de 1901 a 1956 que ocorreu o maior desmatamento, com 8.792 ha sendo incorporados ao uso agrícola, correspondendo a $82 \%$ do total da área (10.669 ha). Nesse período ocorreu a maior taxa de expansão da agricultura nessa região, com uma média de 160 ha sendo convertidos anualmente em áreas agrícolas, correspondentes a uma média de 2 ha desmatados por propriedade a cada cinco anos.

A partir de 1950 iniciou-se no RS, nas áreas agrícolas (originalmente sob florestas), a agricultura mecanizada, com uso de fertilizantes minerais, novas cultivares e equipamentos mecânicos para preparo, semeadura e colheita, o que foi impulsionado pela expansão econômica das culturas do trigo e da soja (Schilling, 1961; Mielniczuk, 1999; Mielniczuk et al., 2003; Rückert, 2003). Especificamente na área em estudo, esse processo iniciou-se de forma mais generalizada somente na década de 1970, coincidindo com o início da expansão do cultivo da soja no Estado e dos programas de recuperação da fertilidade do solo. Portanto, áreas que ainda estavam sob floresta até 1964 passaram a despertar interesse econômico, ocorrendo aumento de 6 \% (568 ha) no desmatamento no período de 1965 a 1975 e de $3 \%$
(354 ha) de 1976 a 1987 (Figura 3). A incorporação de áreas sob vegetação nativa na agricultura refletiuse em taxas de expansão agrícola de 57 ha $a^{-1}$ de 1965 a 1975 e de 32 ha ano-1 de 1976 a 1987. Nos últimos 19 anos avaliados (1988 a 2007), mais 122 ha de mata foram convertidos em áreas agrícolas. Estimativas do IBGE (2007) indicam que 8,6 \% da área do município de Ijuí estava ocupada por matas e florestas nativas em 2006.

\section{Calibração e validação do modelo Century}

Após os ajustes dos coeficientes do modelo realizados na etapa de calibração principal (Quadro 3) e do estabelecimento dos cenários de manejo do solo adotados no Distrito Santana desde o início de sua colonização (Quadro 4), o Century simulou a evolução dos estoques de COS para o período de 1900 a 2050 , considerando a lavoura mais antiga localizada na área 1 , a qual foi submetida ao uso agrícola em 1901, conforme pode ser observado na figura $4 \mathrm{a}$.

Os resultados da validação estatística baseada em dados observados em 10 lavouras iniciadas em diferentes épocas no Distrito Santana, Ijuí (RS), amostradas em 2007 na camada de 0 a $20 \mathrm{~cm}$ do Latossolo de topo, nas áreas 1, 2, 3 e 4 encontramse na figura $4 \mathrm{~b}$.

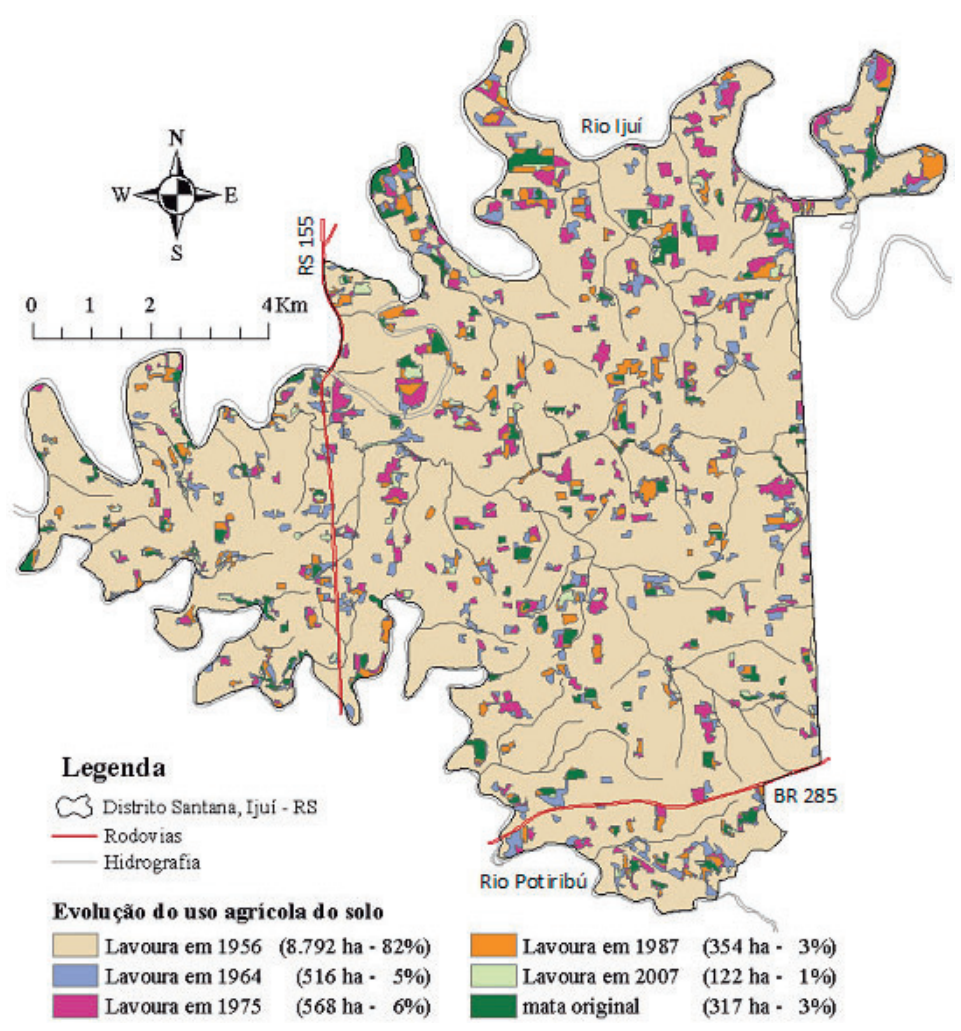

Figura 3. Mapa de evolução de uso agrícola do solo no Distrito Santana, Ijuí-RS, de 1900 (condição original) a 2007. 
(a)

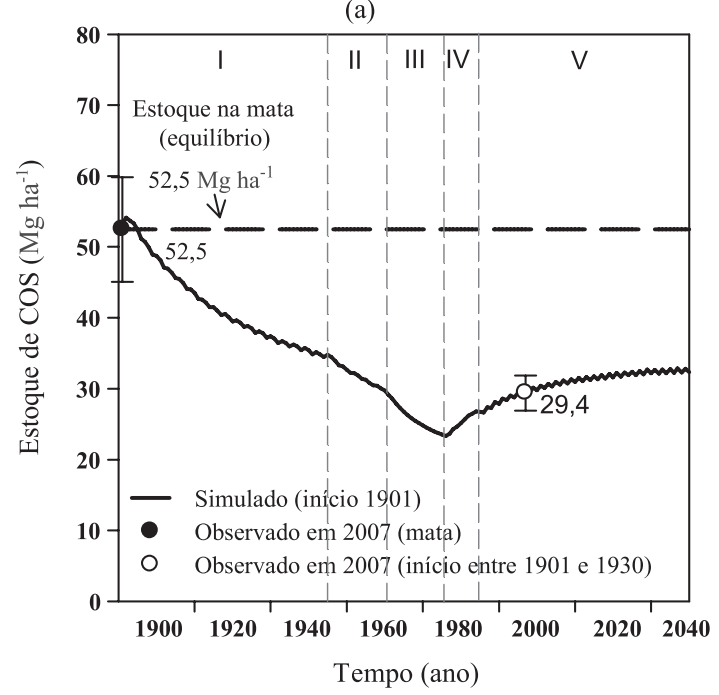

(b)

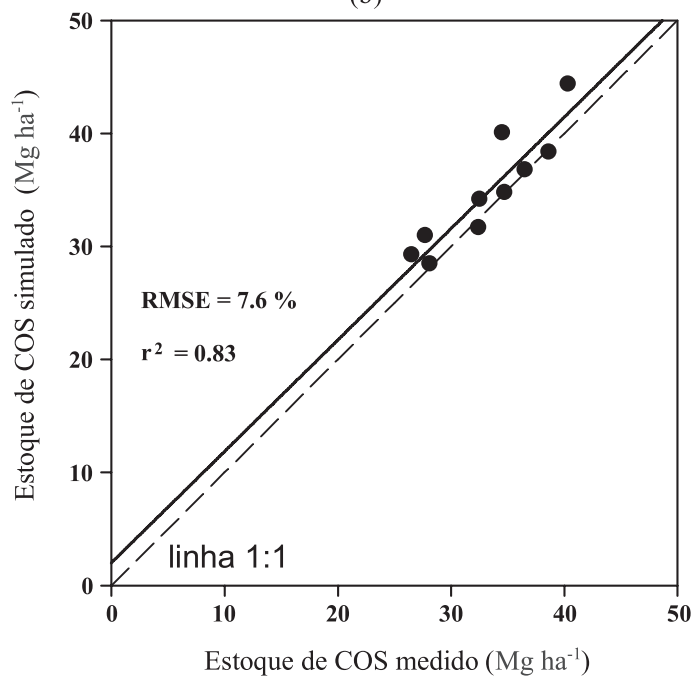

Figura 4. (a) Simulação de calibração principal do modelo Century considerando a conversão de floresta em agricultura em 1901 na área 1 e diferentes cenários de manejo do solo (I- colonial 1; II: colonial 2; III: preparo convencional; IV: preparo reduzido; V: plantio direto "atual") e (b) validação das estimativas do modelo a partir dos estoques de COS medidos e simulados em 2007 em lavouras sob Latossolo de topo no Distrito Santana, Ijuí - RS ( $r=0,91$; RSE = 7,6\%; RMSE_95 \% limite de confiança $=13,8 \%$; $\mathrm{ME}=0,67)$.

Apesar das diferenças entre os valores estimados e medidos em 2007 nas áreas cultivadas, elas não foram estatisticamente significativas, visto que o coeficiente de correlação de Pearson (r) foi de 0,91 para estoques de COS medidos e simulados e a raiz quadrada do erro do modelo, RMSE (Root mean square error of model), que mede a diferença total entre valores medidos e simulados, foi de $7,6 \%$, ficando abaixo do limite de confiança (95\%) de 13,8\% dos valores medidos; além disso, a eficiência da modelagem (ME) foi de 0,67 e positiva (Figura 4b). Esses resultados indicam que o modelo Century, após o ajuste de seus parâmetros (Quadro 3), descreveu adequadamente a variação dos estoques de COS, sendo mais eficiente que a média das observações. Assim, assumiu-se que o modelo tem o mesmo desempenho nas demais classes de solo (Figura 2a) e posições na paisagem (Figura 2b) que ocorrem no Distrito Santana.

\section{Estoques de COS estimados pelo modelo Century}

Os resultados dos estoques de COS estimados pelo modelo Century para o Latossolo de topo nas lavouras iniciadas em 1901, 1957, 1965, 1976 e 1988 encontram-se na figura 5, onde se pode observar que, independentemente do ano em que a mata foi convertida em lavoura, houve redução dos estoques de $\mathrm{C}$ já nos primeiros anos de cultivo.

Conforme verificado em 2007 (Figura 5), lavouras iniciadas entre 1901 e 1956 apresentam o estoque de COS medido de $31,7 \mathrm{Mg}^{\text {ha }}{ }^{-1}$ (média de cinco

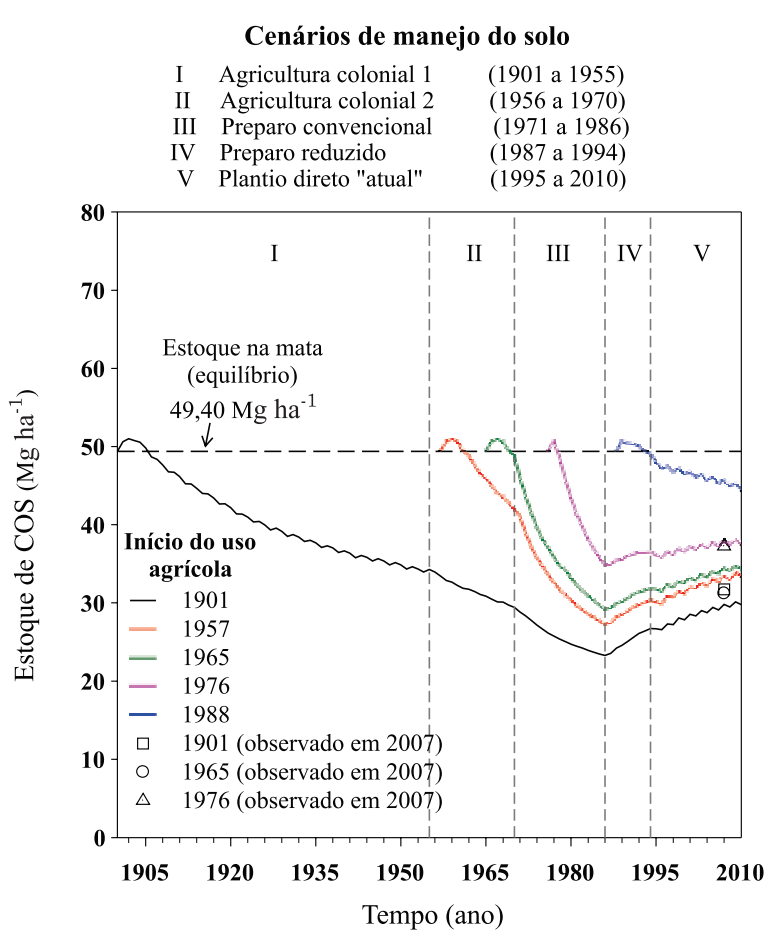

Figura 5. Evolução dos estoques de carbono orgânico do solo (COS) em diferentes épocas de início do uso agrícola, estimada pelo modelo Century na camada de 0 a $20 \mathrm{~cm}$ em Latossolo de topo, considerando diferentes cenários de manejo do solo adotados no Distrito Santana, Ijuí-RS, e valores observados por Bortolon (2008) para o ano de 2007, obtidos em lavouras iniciadas em 1901, 1965 e 1976. 
lavouras) e simulado pelo Century de $29,8 \mathrm{Mg} \mathrm{ha}^{-1}$, enquanto as lavouras iniciadas entre 1965 e 1975 tiveram o estoque medido de $31,2 \mathrm{Mg} \mathrm{ha}^{-1}$ (média de duas lavouras) e o simulado de $34,4 \mathrm{Mg} \mathrm{ha}^{-1}$; as lavouras iniciadas entre 1976 e 1987 apresentam o estoque medido de $37,2 \mathrm{Mg} \mathrm{ha}^{-1}$ (média de três lavouras) e o simulado de $37,9 \mathrm{Mg}^{-1} \mathrm{~h}^{-1}$ (Bortolon, 2008). Nesse caso, a variação entre os dados estimados pelo modelo e os dados observados foi de no máximo 3,2 $\mathrm{Mg}_{\mathrm{ha}}{ }^{-1}$ de COS.

Resultados semelhantes vêm sendo obtidos por outros autores em estudos de mesma natureza realizados em diferentes regiões do Brasil (Cerri et al., 2004; Leite et al., 2004; Lopes et al., 2008; Bortolon et al., 2009; Tornquist et al., 2009). Em estudo realizado por Lopes et al. (2008), o Century estimou estoques de COS de $26,8 \mathrm{Mg} \mathrm{ha}^{-1}$ em lavouras submetidas a 40 anos de cultivo

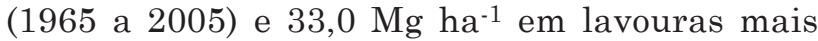
recentes (1985 a 2005), em associação de Neossolo Regolítico (60 \%) e Cambissolo (40 \%) no município de Arvorezinha - RS, enquanto os dados de campo indicaram valores de 24,6 e 29,1 $\mathrm{Mg} \mathrm{ha}^{-1}$ de COS neste solo, respectivamente, considerando os mesmos períodos de uso agrícola.

O Century estimou de forma coerente a alteração dos estoques de COS iniciada com a conversão das áreas sob vegetação nativa em lavouras de cultivos anuais, seguindo um padrão consistente com dados históricos de pesquisa em regiões tropicais e subtropicais (Sanchez, 1976; Greenland et al., 1992; Mielniczuk et al., 2003; Bayer \& Mielniczul, 2008). $\mathrm{O}$ modelo estimou que cerca de $50 \%$ dos estoques de COS em Latossolo foram perdidos devido ao uso agrícola do solo entre 1900 e 1986 (Figura 5), havendo recuperação parcial desses estoques à medida que sistemas conservacionistas de manejo do solo foram adotados. Em estudo realizado por Leite et al. (2004), estimativas do Century evidenciam, em Argissolo Vermelho-Amarelo, redução dos estoques de COS de $56 \%$ em relação ao inicial $\left(64 \mathrm{Mg} \mathrm{ha}^{-1}\right)$ depois de 54 anos (1930 a 1984) de uso agrícola do solo, após a remoção da Floresta Atlântica no Estado de Minas Gerais.

Outro indício de que as estimativas do Century condizem com as tendências históricas de perda dos estoques de COS consta nos dados apresentados por Abrão \& Azolin (1970) referentes ao levantamento de solos do município de Ijuí, cujo mapa de solos serviu de base para o presente estudo, já que lavouras com cultivos anuais, conduzidas sobre Latossolo e que foram amostradas na década de 1960, apresentaram estoques médios de COS de 25,0 $\mathrm{Mg} \mathrm{ha}^{-1}$, equivalentes à massa da camada de 0 a $20 \mathrm{~cm}$ da mata nativa. Apesar de não haver informações exatas a respeito do ano em que as lavouras amostradas foram submetidas ao uso agrícola, trata-se de amostras de solo obtidas durante o período de transição entre dois importantes cenários de manejo do solo, caracterizado por substituição da agricultura colonial de subsistência pela agricultura mecanizada e empresarial, representando assim o período cujos estoques de COS já estavam bastante reduzidos, mas ainda sujeitos a mais perdas devido à adoção do preparo convencional (PC) do solo que se iniciava na região (Mielniczuk et al., 2003).

As simulações nos diferentes elementos da paisagem nas lavouras iniciadas em diferentes épocas evidenciaram tendências similares; por isso, foram apresentadas e discutidas somente as simulações considerando lavouras iniciadas em 1901 (mais antiga) e 1988 (mais recente) em todas as classes de solo e posições na paisagem (Quadro 5). Nos demais anos de início do uso agrícola dos solos (1957, 1965 e 1976), os estoques de COS foram intermediários, ficando dentro da variação estimada nas lavouras mais antigas e nas mais recentes (Figura 5). No entanto, nas etapas de espacialização das estimativas de COS pelo Century foram consideradas as cinco situações relativas ao início do uso agrícola do solo.

Comparativamente aos topos, os estoques de COS estimados pelo Century são menores nas encostas e maiores nas áreas deposicionais para o mesmo tipo de solo e ano de conversão da mata em lavoura (Quadro 5). Nas lavouras submetidas ao uso agrícola em 1901, o Century estimou, para o Latossolo, decréscimos de até $56 \%$ (de 49,4 para 21,9 $\mathrm{Mg} \mathrm{ha}^{-1}$, nas encostas) do estoque original de COS até o final do período de PC, em 1986. A adoção dos sistemas de manejo conservacionistas preparo reduzido (PR) em 1987 e plantio direto (PD) em 1995 - proporcionou a reversão desse processo, passando a haver acúmulo de $\mathrm{C}$ no solo ao longo dos anos. Contudo, esses acúmulos não garantiram recuperação dos estoques de COS até a condição inicial, estando 40 \% abaixo disso em 2007. Esses resultados são coerentes com os observados por outros autores em estudos na região do Planalto Riograndense (Pöttker, 1977; Cintra et al., 1983; Debarba, 2002; Tornquist et al., 2009).

Estimativas obtidas por Tornquist (2007), utilizando o Century, indicam perdas do estoque de COS entre 49 e $33 \%$ após 80 anos de uso agrícola (1900 a 1980) com a implantação da agricultura convencional em solos sob mata, na região de Ibirubá, RS. No entanto, a adoção de sistemas conservacionistas de manejo do solo levou a aumentos nos estoques de COS até 2005 , ficando $40 \%$ abaixo do original no Neossolo Regolítico e chegando a superar o estoque original em até $3 \%$ em Latossolo Vermelho de 
Quadro 5. Estoques de carbono orgânico do solo (COS) estimados pelo modelo Century na camada de 0 a $20 \mathrm{~cm}$ de mata nativa e em lavouras iniciadas em 1901 e em 1988, considerando o último ano de adoção dos diferentes cenários de manejo nas diferentes classes de solo e posições na paisagem, no Distrito Santana, Ijuí-RS

\begin{tabular}{|c|c|c|c|c|c|c|c|c|}
\hline \multirow{3}{*}{ Unidade de simulação } & \multirow{3}{*}{$\begin{array}{c}\text { Mata nativa } \\
1900\end{array}$} & \multicolumn{7}{|c|}{ Lavoura } \\
\hline & & \multicolumn{5}{|c|}{ Início em 1901} & \multicolumn{2}{|c|}{ Início em 1988} \\
\hline & & 1955 & 1970 & 1986 & 1994 & 2007 & 1994 & 2007 \\
\hline \multicolumn{9}{|l|}{ Latossolo } \\
\hline $\begin{array}{l}\text { Topo } \\
\text { Encosta } \\
\text { Deposicional }\end{array}$ & 49,4 & $\begin{array}{l}34,3 \\
33,6 \\
38,2\end{array}$ & $\begin{array}{l}29,4 \\
28,3 \\
35,2\end{array}$ & $\begin{array}{l}23,3 \\
21,9 \\
31,1\end{array}$ & $\begin{array}{l}26,7 \\
25,2 \\
34,9\end{array}$ & $\begin{array}{l}29,8 \\
28,2 \\
38,0\end{array}$ & $\begin{array}{l}49,1 \\
48,8 \\
49,8\end{array}$ & $\begin{array}{l}45,6 \\
45,2 \\
46,6\end{array}$ \\
\hline \multicolumn{9}{|l|}{ Chernossolo } \\
\hline $\begin{array}{l}\text { Topo } \\
\text { Encosta } \\
\text { Deposicional }\end{array}$ & 49,4 & $\begin{array}{l}34,2 \\
33,7 \\
37,1\end{array}$ & $\begin{array}{l}29,9 \\
29,1 \\
34,2\end{array}$ & $\begin{array}{l}24,1 \\
22,9 \\
29,8\end{array}$ & $\begin{array}{l}27,4 \\
26,2 \\
33,5\end{array}$ & $\begin{array}{l}30,4 \\
29,1 \\
36,4\end{array}$ & $\begin{array}{l}48,8 \\
48,7 \\
49,4\end{array}$ & $\begin{array}{l}45,3 \\
45,0 \\
46,0\end{array}$ \\
\hline \multicolumn{9}{|l|}{ Neossolo Regolítico } \\
\hline $\begin{array}{l}\text { Topo } \\
\text { Encosta } \\
\text { Deposicional }\end{array}$ & 63,2 & $\begin{array}{l}31,2 \\
30,8 \\
33,8\end{array}$ & $\begin{array}{l}26,5 \\
25,8 \\
30,2\end{array}$ & $\begin{array}{l}20,9 \\
19,9 \\
25,9\end{array}$ & $\begin{array}{l}23,7 \\
22,6 \\
28,9\end{array}$ & $\begin{array}{l}26,1 \\
25,0 \\
31,4\end{array}$ & $\begin{array}{l}56,6 \\
56,4 \\
57,2\end{array}$ & $\begin{array}{l}46,3 \\
45,7 \\
46,7\end{array}$ \\
\hline \multicolumn{9}{|l|}{ Neossolo Flúvico } \\
\hline Deposicional & 47,9 & 33,5 & 30,4 & 26,4 & 30,0 & 32,9 & 47,1 & 42,9 \\
\hline
\end{tabular}

textura argilosa. Os incrementos nos estoques de COS estimados por esse autor foram maiores que os obtidos no presente estudo, e a principal razão para isso é a inclusão de milho na rotação de culturas na região de Ibirubá a partir de 1985, o que não ocorreu no Distrito Santana, em Ijuí.

Para as lavouras iniciadas nos anos de 1957, 1965, 1976 e 1988, em estudo, estimaram-se perdas sucessivamente menores e acúmulos maiores, porém mesmo em lavouras iniciadas em 1988 (Quadro 5), já no período conservacionista de manejo (PR), não foi possível manter os estoques originais até 2007, havendo redução destes.

Tendências semelhantes foram estimadas para as demais classes de solo em estudo, exceto no Neossolo Flúvico, onde a dinâmica de alteração dos estoques de COS pelo uso agrícola foi diferenciada em razão de ocorrerem em relevo plano e próximo aos cursos d’água, sendo áreas deposicionais sujeitas às inundações temporárias que reduzem a atividade microbiana e que possuem, de modo geral, menores perdas e maiores acúmulos de COS. Nas encostas do Chernossolo, as lavouras mais antigas (iniciadas em 1901) evidenciaram perdas de $54 \%$ do seu estoque original até 1986 e recuperação parcial até 2007 (57\% do original), ao passo que no Neossolo Regolítico o Century estimou perda de 68 \% (63,2 para $19,9 \mathrm{Mg} \mathrm{ha}^{-1}$ ) do COS estocado na camada de 0 a $20 \mathrm{~cm}$ sob vegetação nativa até 1986 , e a adoção de práticas conservacionistas de manejo do solo a partir de 1987 garantiu o controle dessas perdas, possibilitando o acúmulo de $6,2 \mathrm{Mg} \mathrm{ha}^{-1}$ até 2007 (ainda $60 \%$ abaixo do original).
Apesar de as taxas de erosão e deposição atribuídas serem iguais para as diferentes classes de solo, variando somente entre os elementos na paisagem e cenários de manejo (Quadro 4), a quantidade de C efetivamente perdida ou acumulada pelos processos de erosão e deposição, respectivamente, foram diferentes entre as classes de solos, considerando o mesmo elemento da paisagem, para lavouras iniciadas em 1901 e em 1988 (Quadro 6). Isso ocorre porque as diferentes classes de solo apresentam diferentes estoques de COS, que, em última análise, determinam a quantidade de $\mathrm{C}$ perdido ou acumulado pelos processos de erosão ou deposição, respectivamente.

Os resultados apresentados no quadro 6 evidenciam a importância da adoção de práticas conservacionistas de manejo do solo, pois, quando se comparam as perdas de COS associadas à erosão estimada pelo Century nas lavouras iniciadas em 1901 em todas as classes de solos, mais de $90 \%$ do COS perdido até 2007 corresponde às perdas por erosão causadas pela adoção de práticas de manejo de solo inadequadas até 1986 - cerca de $30 \%$ desse valor refere-se aos 15 anos de preparo convencional do solo (1971 a 1986). Isso porque o revolvimento intensivo do solo, associado aos períodos em que este permanecia descoberto e com a remoção dos resíduos da cultura do trigo pelas queimadas, tornava-o altamente suscetível à erosão (Cassol, 1986; Mielniczuk, 1999). Como era esperarado, acúmulos de mesmas proporções foram estimados para as superfícies deposicionais, com cerca de $90 \%$ do total de COS acumulado até 2007 correspondendo ao período anterior a 1986 . 
Quadro 6. Erosão (-) ou deposição (+) cumulativa de carbono orgânico do solo (COS) na camada de 0 a $20 \mathrm{~cm}$ de lavouras iniciadas em 1901 e em 1988, nas diferentes classes de solo e posições na paisagem, estimada pelo modelo Century pela variável de saída SCLOSA(1), no Distrito Santana, Ijuí-RS

\begin{tabular}{|c|c|c|c|c|c|c|c|}
\hline \multirow{3}{*}{ Unidade de simulação } & \multicolumn{7}{|c|}{ Erosão (-) ou deposição (+) de C } \\
\hline & \multicolumn{5}{|c|}{ Início em 1901} & \multicolumn{2}{|c|}{ Início em 1988} \\
\hline & 1955 & 1970 & 1986 & 1994 & 2007 & 1994 & 2007 \\
\hline Latossolo & & & & $\mathrm{Mg} \mathrm{ha}^{-}$ & & & \\
\hline $\begin{array}{l}\text { Topo } \\
\text { Encosta } \\
\text { Deposicional }\end{array}$ & $\begin{array}{r}-4,1 \\
-5,0 \\
+1,4\end{array}$ & $\begin{array}{r}-6,0 \\
-7,5 \\
+2,1\end{array}$ & $\begin{array}{r}-8,9 \\
-11,2 \\
+3,4\end{array}$ & $\begin{array}{r}-9,3 \\
-11,8 \\
+3,6\end{array}$ & $\begin{array}{r}-9,6 \\
-12,2 \\
+3,8\end{array}$ & $\begin{array}{r}-0,6 \\
-0,9 \\
+0,2\end{array}$ & $\begin{array}{r}-0,9 \\
-1,6 \\
+0,4\end{array}$ \\
\hline \multicolumn{8}{|l|}{ Chernossolo } \\
\hline $\begin{array}{l}\text { Topo } \\
\text { Encosta } \\
\text { Deposicional }\end{array}$ & $\begin{array}{r}-3,0 \\
-3,7 \\
+1,0\end{array}$ & $\begin{array}{r}-4,4 \\
-5,6 \\
+1,5\end{array}$ & $\begin{array}{r}-6,6 \\
-8,3 \\
+2,4\end{array}$ & $\begin{array}{l}-6,9 \\
-8,8 \\
+2,6\end{array}$ & $\begin{array}{r}-7,1 \\
-9,1 \\
+2,7\end{array}$ & $\begin{array}{r}-0,4 \\
-0,7 \\
+0,2\end{array}$ & $\begin{array}{l}-0,7 \\
-1,2 \\
+0,3\end{array}$ \\
\hline \multicolumn{8}{|c|}{ Neossolo Regolítico eutrófico } \\
\hline $\begin{array}{l}\text { Topo } \\
\text { Encosta } \\
\text { Deposicional }\end{array}$ & $\begin{array}{r}-2,9 \\
-3,6 \\
+1,0\end{array}$ & $\begin{array}{r}-4,2 \\
-5,2 \\
+1,5\end{array}$ & $\begin{array}{r}-6,0 \\
-7,6 \\
+2,2\end{array}$ & $\begin{array}{r}-6,3 \\
-8,0 \\
+2,3\end{array}$ & $\begin{array}{r}-6,4 \\
-8,2 \\
+2,4\end{array}$ & $\begin{array}{r}-0,5 \\
-0,8 \\
+0,2\end{array}$ & $\begin{array}{l}-0,8 \\
-1,3 \\
+0,3\end{array}$ \\
\hline \multicolumn{8}{|l|}{ Neossolo Flúvico } \\
\hline Deposicional & $+0,9$ & $+1,4$ & $+2,2$ & $+2,3$ & $+2,4$ & $+0,1$ & $+0,2$ \\
\hline
\end{tabular}

\section{Distribuição espacial dos estoques de COS}

A integração das informações obtidas de evolução de uso agrícola dos solos do Distrito Santana com as estimativas do modelo Century para as diferentes unidades de simulação (solo-elemento da paisagem-evolução de uso do solo), pela utilização de ferramentas de geoprocessamento, permite visualizar de forma espacializada os impactos das mudanças no uso e manejo do solo sobre os estoques de COS ao longo do tempo (Figura 6).

A figura 6 mostra que a maior parte da área do Distrito Santana (6.020 ha, $56 \%$ ) apresenta estoques de COS inferiores a $29,8 \mathrm{Mg} \mathrm{ha}^{-1} \mathrm{em} \mathrm{2007,} \mathrm{estando}$ principalmente associados as áreas submetidas ao uso agrícola entre 1901 e 1956 (Figura 3). Por outro lado, os maiores estoques de COS estão associados às áreas sob vegetação nativa (317 ha, $3 \%$ ), visto que as mudanças no uso e manejo dos solos dessa região ocorridas ao longo dos anos determinaram estoques de COS sempre inferiores aos originais até 2007 , segundo dados observados (Figura 5) e estimativas do modelo Century, mesmo com acúmulos de $\mathrm{C}$ no solo obtidos pela adoção de sistemas conservacionistas de manejo a partir de 1987. Além disso, estoques variando entre 29,9 e $34,7 \mathrm{Mg} \mathrm{ha}^{-1}$ ocorrem em $25 \%$ da área (2.621 ha) e podem ser observados próximos à rede de drenagem, onde há acúmulo de $\mathrm{C}$ devido ao processo de deposição de sedimentos (áreas deposicionais). Os demais $16 \%$ da área correspondem às áreas cujos estoques de COS variam de 34,8 a
41,2 $\mathrm{Mg} \mathrm{ha}^{-1}$ (1.589 ha, $\left.15 \%\right)$, principalmente associados a áreas submetidas ao uso agrícola entre 1957 e 1987, e de 41,3 a 47,5 $\mathrm{Mg} \mathrm{ha}^{-1}$ (122 ha, $1 \%$ ), associados a áreas mais recentemente submetidas ao uso agrícola (entre 1988 e 2007).

A variação das quantidades de COS estocadas em função das mudanças no uso e manejo do solo ao longo dos anos, associada com a distribuição espacial desses estoques, permitiu estimar os estoques totais de COS na camada de 0 a $20 \mathrm{~cm}$ nos solos do Distrito Santana (Ijuí-RS). Essa abordagem, obtida por meio da modelagem espacialmente explícita e técnicas de geoprocessamento, possibilitou uma estimativa mais detalhada da variação dos estoques de COS da região (Quadro 7).

Até 1900, os solos da área em estudo (10.669 ha) estocaram um total de $550,9 \times 10^{3} \mathrm{Mg}$ de COS, sendo o Latossolo responsável por $57 \%\left(314,1 \times 10^{3} \mathrm{Mg}\right)$ desse valor, o que é proporcional à área ocupada por essa classe de solo (60 \%) (Figura 2a). O Neossolo Regolítico, ocorrendo em $17 \%$ da área, representava $21 \%\left(115,9 \times 10^{3} \mathrm{Mg}\right)$ do estoque total de COS em 1900, enquanto o estoque original do Chernossolo correspondia a $13 \%\left(72,6 \times 10^{3} \mathrm{Mg}\right)$ e o do Neossolo Flúvico, a $9 \%\left(48,3 \times 10^{3} \mathrm{Mg}\right)$ do total.

O cultivo do solo a partir de 1901 determinou redução de $28,1 \%\left(155,1 \times 10^{3} \mathrm{Mg}\right)$ nos estoques totais de COS na camada de 0 a $20 \mathrm{~cm}$ até 1955 e de mais $11,1 \%\left(44,1 \times 10^{3} \mathrm{Mg}\right)$ até 1970 , totalizando a perda de $199,2 \times 10^{3} \mathrm{Mg}$ de COS durante o período 
de agricultura colonial (1901 a 1970). No período em que o solo foi cultivado em preparo convencional mecanizado (1971 a 1986), as perdas de COS foram ampliadas em mais $21,3 \%$, estimando-se que em 1986 os solos apresentavam o menor estoque total de COS na camada de 0 a $20 \mathrm{~cm}$ do Distrito

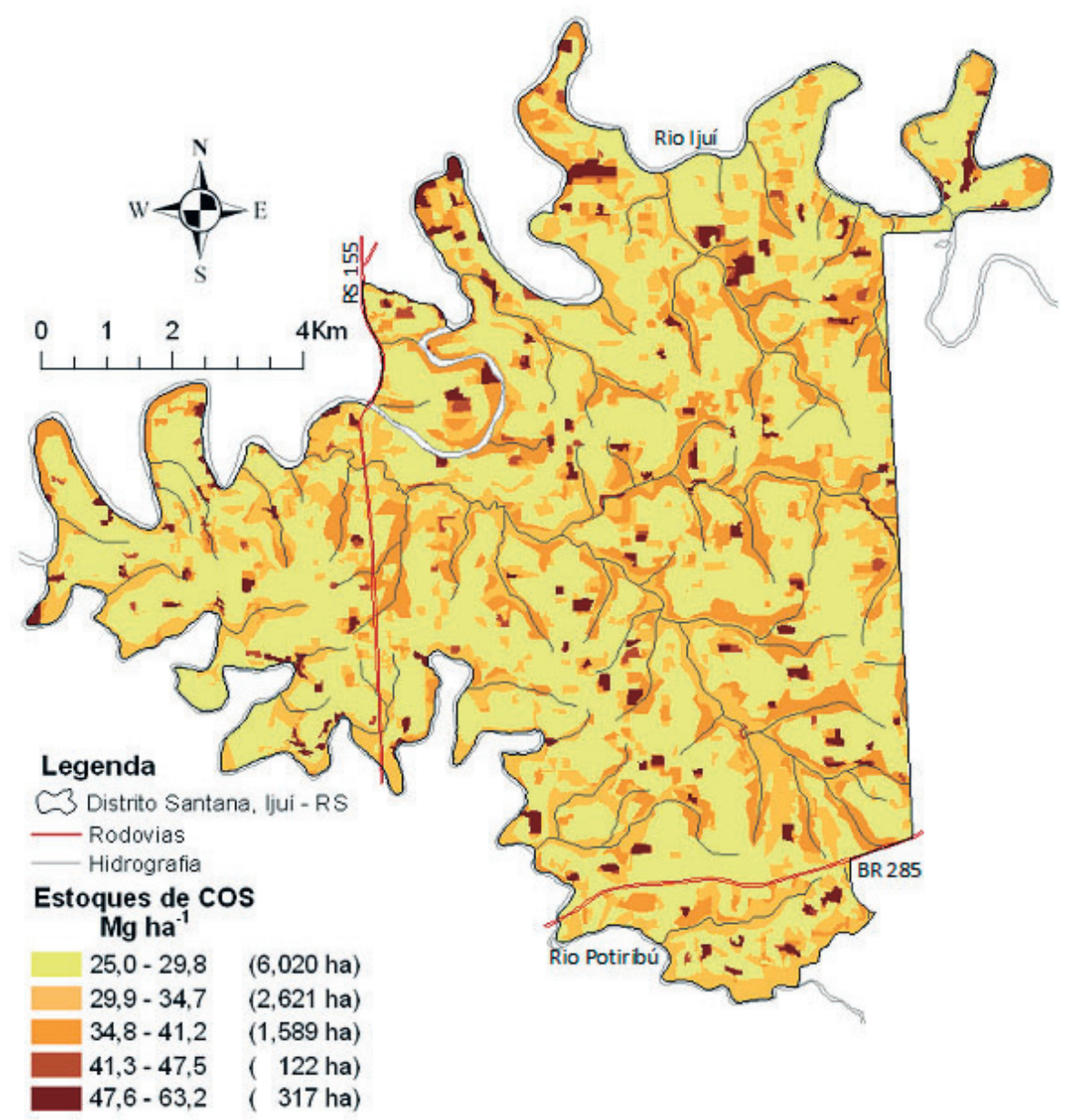

Figura 6. Distribuição espacial dos estoques de carbono orgânico do solo (COS), em 2007, nos solos do Distrito Santana, Ijuí-RS, estimados pelo modelo Century, considerando diferentes épocas de início do uso agrícola, cenários de manejos do solo e posição na paisagem. Estoques de COS nas lavouras em massa equivalente à camada de 0 a $20 \mathrm{~cm}$ da mata original.

Quadro 7. Estoques totais de carbono orgânico do solo (COS) e sua variação de 1900 a 2007 nas diferentes classes de solo do Distrito Santana, Ijuí-RS, no último ano de adoção dos diferentes cenários de manejo nas diferentes classes de solo, considerando a massa equivalente de solo na camada de 0 a $20 \mathrm{~cm}$ da mata

\begin{tabular}{|c|c|c|c|c|c|c|}
\hline \multirow{2}{*}{ Classe de solo } & \multicolumn{6}{|c|}{ Estoque total de COS } \\
\hline & 1900 & 1955 & 1970 & 1986 & 1994 & 2007 \\
\hline & \multicolumn{6}{|c|}{$10^{3} \mathrm{Mg}$} \\
\hline $\begin{array}{l}\text { Latossolo } \\
\text { Chernossolo } \\
\text { Neossolo Regolítico } \\
\text { Neossolo Flúvico } \\
\text { Total }\end{array}$ & $\begin{array}{r}314,1 \\
72,6 \\
115,9 \\
48,3 \\
550,9\end{array}$ & $\begin{array}{r}239,0 \\
54,0 \\
67,8 \\
35,0 \\
395,8\end{array}$ & $\begin{array}{r}212,7 \\
48,4 \\
59,4 \\
31,9 \\
351,7\end{array}$ & $\begin{array}{r}164,0 \\
39,1 \\
46,3 \\
27,4 \\
276,8\end{array}$ & $\begin{array}{r}184,0 \\
43,9 \\
50,8 \\
30,9 \\
309,6\end{array}$ & $\begin{array}{r}201,5 \\
47,9 \\
54,7 \\
33,7 \\
337,7\end{array}$ \\
\hline Diferença em relação ao original (em \%) & & $-28,1$ & $-36,2$ & $-49,7$ & $-43,8$ & $-38,7$ \\
\hline Diferença em relação à data anterior (em \%) & & $-28,1$ & $-11,1$ & $-21,3$ & $+11,8$ & $+9,1$ \\
\hline
\end{tabular}


Santana, desde 1900: $276,8 \times 10^{3} \mathrm{Mg}(49,7 \%$ abaixo do original). A mudança no sistema de manejo do solo utilizado, passando do PC para cenários conservacionistas a partir de 1987, proporcionou inicialmente redução das perdas de $\mathrm{C}$, seguida por acúmulo desse nutriente no solo e consequente aumento dos estoques totais de $\operatorname{COS}$ ao longo dos anos de adoção desses cenários, estimando-se acréscimo de 11,8 \% no estoque total em 1994, em relação ao período anterior; com a adoção do PD a partir de 1995, estimou-se que em 2007 o estoque total de COS do Distrito Santana aumentou em $22 \%$ em relação a 1986 , porém permaneceu $38,7 \%$ abaixo do original.

\section{CONCLUSÃO}

O modelo Century, depois de calibrado, estimou adequadamente a dinâmica espaço-temporal do C em propriedades rurais do Distrito Santana, em Ijuí, RS, reproduzindo a evolução dos estoques de COS ocorrida nessa região. Segundo essas estimativas, a adoção de práticas conservacionistas de manejo garante a redução das perdas de $\mathrm{C}$ causadas pelo processo erosivo, passando a haver aumento nos estoques de COS no solo.

\section{AGRADECIMENTOS}

À UNIJUI, em especial aos professores da Faculdade de Agronomia Sandra B. Vicenci Fernandes e Valmir de Quadros. Aos chefes dos escritórios municipais da Emater/RS de Ijuí e de Bozano, Edio Korb e Edivin Bernich, respectivamente. Às famílias Kosloski, Lucacheski, Quadros, Ledermann, Gentarski e Pietrzak, bem como a todas as famílias de agricultores do Distrito Santana, Ijuí, RS, que de alguma forma contribuíram para a realização deste trabalho.

Este estudo foi financiado pelo PRONEX, numa parceria entre CNPq e FAPERGS (Fundação de Amparo à Pesquisa do Estado do Rio Grande do Sul). $\mathrm{O}$ primeiro autor agradece ainda ao $\mathrm{CNPq}$ a bolsa de estudos concedida.

\section{LITERATURA CITADA}

ABRÃO, U.R. \& AZOLIN, M.A.D. Levantamento e utilização agrícola dos solos do município de Ijuí. Porto Alegre, Instituto Nacional de Colonização e Reforma Agrária INCRA. Secretaria da Agricultura do Estado do Rio Grande do Sul/Departamento de Recursos Naturais Renováveis, 1970. (Texto Mimeografado)
BAYER, C.; MARTIN-NETO, L.; MIELNICZUK, J.; PAVINATO, A. \& DIEKOW, J. Carbon sequestration in two Brazilian Cerrado soils under no-till. Soil Tillage Res., 86:237-24, 2006.

BAYER, C. \& MIELNICZUK, J. Dinâmica e função da matéria orgânca. In: SANTOS, G.A. \&. CAMARGO, F.A.O., eds. Fundamentos da matéria orgânica do solo - Ecossistemas tropicais e subtropicais. 2.ed. Porto Alegre, Metropole, 2008. p.7-18.

BENITES, V.M.; MACHADO, P.L.O.A.; FIDALGO, E.C.C.; COELHO, M.R. \& MADARI, B.E. Pedotransfer functions for estimating soil bulk density from existing soil survey reports in Brazil. Geoderma, 139:90-97, 2007.

BLAKE, G.R. \& HARTGE, K.H. Bulk density. In: KLUTE, A., ed. Methods of soil analysis. Physical and chemical methods. 2.ed. Madison, American Society of AgronomySoil Science of America, 1986.Part 1. p.363-375 (Agronomy Monograph, 9)

BORTOLON, E.S.O. Simulação do impacto da agricultura sobre os estoques de carbono orgânico do solo e o balanço de $\mathrm{CO}_{2}$ regionais integrando o modelo Century e sistemas de informação geográfica. Porto Alegre, Universidade Federal do Rio Grande do Sul, 2008. 161p. (Tese de Doutorado)

BORTOLON, E.S.O.; MIELNICZUK, J.; TORNQUIST, C.G.; LOPES, F. \& FERNANDES, F.F. Simulação da dinâmica do carbono e nitrogênio em um Argissolo do Rio Grande do Sul usando o modelo Century. R. Bras. Ci. Solo, 33:1635$1646,2009$.

BORTOLON, E.S.O.; MIELNICZUK, J.; TORNQUIST, C.G.; LOPES, F. \& BERGAMASCHI, H. Validation of the Century model to estimate the impact of agriculture on soil organic carbon in Southern Brazil. Geoderma, 167/168:156166, 2011.

BRASIL. Ministério do Exército. Diretoria de Serviços Geográficos. Folha topográfica 1:50.000 Ijuí. Brasília, 1980. (Folha SH.22 VAI3, MI-2915/3)

BRUM, A.J. Modernização da agricultura no Planalto Gaúcho. Ijuí, FIDENE, 1983. 204p.

CENTER OF AGRICULTURAL AND RURAL DEVELOMENT - CARD. Iowa State University. Disponível em: <http:// www.card.iastate.edu/environment/interactive_programs. aspx>. Acesso em: 29 de ago. de 2008.

CASSOL, E.A. Erosão do solo: Influência do uso agrícola, do manejo e preparo do solo. 2.ed. Porto Alegre, 1986. 223p. (Publicação IPRNR, 15)

CERRI, C.E.P.; COLEMAN, K.; JENKINSON, D.S.; BERNOUX, M.; VECTORIA, R. \& CERRI, C.C. Modeling soil carbon from forest and pasture ecosystem of Amazon, Brazil. Soil Sci. Soc. Am. J., 67:1879-1887, 2003.

CERRI, C.E.P.; PAUSTIAN, K.; BERNOUX, M.; VICTORIA, R.L.; MELILLO, J.M. \& CERRI, C.C. Modeling changes in soil organic matter in Amazon forest to pasture conversion with the Century model. Global Change Biol., 10:815-832, 2004 . 
CINTRA, F.L.D.; MIELNICZUK, J. \& SCOPEL, I. Caracterização do impedimento mecânico em um Latossolo Roxo do Rio Grande do Sul. R. Bras. Ci. Solo, 7:323-327, 1983.

DEBARBA, L. Simulação pelo modelo Century do impacto da agricultura sobre o estoque de carbono orgânico em solos do Planalto Riograndense. Porto Alegre, Universidade Federal do Rio Grande do Sul, 2002. 172p. (Tese de Doutorado)

ELLERT, B.H. \& BETTANY, J.R. Calculation of organic matter and nutrients stored in soils under contrasting management regimes. Can. J. Soil Sci., 75:529-538, 1995.

EMPRESA BRASILEIRA DE PESQUISA AGROPECUÁRIA EMBRAPA. Centro Nacional de Pesquisa do Solo. Manual de métodos e análise de solo. 2.ed. Rio de Janeiro, 1997. 212 p.

EMPRESA BRASILEIRA DE PESQUISA AGROPECUÁRIA EMBRAPA. Centro Nacional de Pesquisa do Solo. Sistema brasileiro de classificação de solos. Rio de Janeiro, 2006. 306p.

ENVIRONMENTAL SYSTEMS RESEARCH INSTITUTE ESRI. ArcGis 9.0. Redland, 2003.

GOMES, A.G. \& VARRIALE, M.C. Modelagem de ecossistemas: Uma introdução. 2.ed. Santa Maria, Universidade Federal de Santa Maria, 2004. 503p.

GREENLAND, D.J.; WILD, A. \& ADAMS, D. Organic matter dynamics in soils of the tropics - From myth to complex reality. In: LAL, R. ed. Myths and science of soil in the tropics. Madison, ASA/SSSA, 1992. p.17-33.

INSTITUTO BRASILEIRO DE GEOGRAFIA E ESTATÍSTICA - IBGE. Censo Agropecuário de 2006. Rio de Janeiro, 2007.

JENNESS. Topographic position index extention for ArcView 3.x. 2008. Disponível em: <http://www.jennessnt.com/arcview/ tpi>. Acesso em: 12 de maio de 2008.

LAL, R. Potential of desertification control to sequester carbon and mitigate the greenhouse effect. Climatic Change, 51:35-72, 2001.

LAL, R. Soil carbon dynamics in cropland and rangeland. Environ. Pollution, 116:353-362, 2002.

LEAL, M.A.A. Proposta de modelo de simulação no estudo da dinâmica da matéria orgânica do solo. Seropédica, Universidade Federal Rural do Rio de Janeiro, 1996. 111p. (Tese de Mestrado)

LEITE, L.F.C.; MENDONÇA, E.S.; MACHADO, P.L.O.A.; FERNANDES FILHO, E.I. \& NEVES, J.C.L. Simulating trends in soil organic carbon of an Acrisol under no-tillage and disc-plow systems using the Century model. Geoderma, 120:283-295, 2004.

LOPES, F.; MERTEN, G.H.; MIELNICZUK, J.; TORNQUIST, C.G. \& OLIVEIRA, E.S. Simulação da dinâmica do carbono do solo numa microbacia rural pelo modelo Century. Pesq. Agropec. Bras., 43:745-753, 2008.

METHEREL, A.K.; HARVING, L.A.; COLE, C.V. \& PARTON, W.J. Century: Soil organic matter model environment. Technical documentation agrossystem version 4.0. Fort Collins, USDA-ARS, 1994. 123p. (Great Plains System Research Unit. Technical Report, 4)
MIELNICZUK, J. Matéria orgânica e a sutentabilidade de sistemas agrícolas. In: SANTOS, G.A. \& CAMARGO, F.A.O., eds. Fundamentos da matéria orgânica do solo: Ecossistemas tropicais e subtropicais. Porto Alegre, Gênesis, 1999. 508p.

MIELNICZUK, J.; BAYER, C.; VEZZANI, F.M.; LOVATO, T.; FERNANDES, F.F. \& DEBARBA, L. Manejo de solo e culturas e sua relação com os estoques de carbono e nitrogênio do solo. In: CURI, N.; MARQUES, J.J.; GUILHERME, L.R.G.; LIMA, J.M.; LOPES, A.S. \& ALVAREZ V., V.H., eds. Tópicos em ciência do solo. Viçosa, MG, Sociedade Brasileira de Ciência do Solo, 2003. v.3. p.209-241.

NELSON, D.W. \& SOMMERS, L.E. Total carbon, organic carbon and organic matter. In: SPARKS, D.L.; SOLTANPOUR, P.N.; TABATABAI, M.A.; JOHNSON, C.T. \& SUMNER, M.E., eds. Methods of soil analysis; Chemical methods. Madison, Soil Science Society of America, 1996. Part 3. p.961-1110. (Book Series, 5)

NØRGAARD, A. Spatial modeling of soil organic carbon by linking Century and GIS.. Copenhagen, University of Copenhagen, 2004. 170p. (Tese de Mestrado)

PARFITT, R.L.; THENG, B.K.G.; WHITTON, J.S. \& SHEPHERD, T.G. Effects of clay minerals and land use on organic matter pools. Geoderma, 75:1-12, 1997.

PARTON, W.J.; SCHIMEL, D.S.; COLE, C.V. \& OJIMA, D.S. Analysis of factors controlling soil organic matter levels in great plains grasslands. Soil Sci. Soc. Am. J., 51:11731179, 1987.

PAUSTIAN, K.; PARTON, W.J. \& PERSSON, J. Modelling soil organic matter in organic-amended and nitrogen-fertilized long-term plots. Soil Sci. Soc. Am. J., 56:476-488, 1992.

PENNOCK, D.J. \& FRICK, A.H. The role of fiels studies in landscape-scale applications of process models: an example of soil redistribution and soil organic carbon modeling using Century. Soil Tillage Res., 58:183-191, 2001.

PÖTTKER, D. Efeitos do tipo de solo, tempo de cultivo e da calagem sobre a mineralização da matéria orgânica em solos do Rio Grande do Sul. Porto Alegre, Universidade Federal do Rio Grande do Sul, 1977. 85p. (Tese de Mestrado)

RÜCKERT, A. Metamorfoses do território: A agricultura de trigo/soja no Planalto Médio Rio-grandense 1930/1990. Porto Alegre, Universidade Federal do Rio Grande do Sul, 2003. 223p.

SANCHES, P.A. Properties and management of soils in the tropics. New York, John Wiley, 1976. 618p.

SCHILLING, P.R. Crise econômica do Rio Grande do Sul: I A crise agro-pecuária. Porto Alegre, Difusão de Cultura Técnica, 1961. 175p.

SIEKIERSKI, M. \& LAZZAROTTO, D. Povoado Santana conta sua história. Ijuí, UNIJUÍ, 1987. 87p. (Coleção Centenário de Ijuí, 4)

SILVA, L.M.V. \& PASQUAL, A. Dinâmica da matéria orgânica do solo com ênfase ao ecossistema tropical. Energia Agric., 14:13-24, 1999. 
SILVEIRA, A.M.; VICTORIA, R.L.; BALLESTER, M.V.; CAMARGO, P.B.; MARTINELLI, L.A. \& PICCOLO, M.C. Simulação dos efeitos das mudanças de uso da terra na dinâmica do carbono do solo na bacia do rio Piracicaba. Pesq. Agropec. Bras., 35:389-399, 2000.

SMITH, P.; SMITH, J.U.; POWLSON, D.S.; MCGILL, W.B.; ARAH, J.R.M.; CHERTOV, O.G.; COLEMAN, K.; FRANKO, U.; FROLKING, S.; JENKINSON, D.S.; JENSEN, L.S.; KELLY, R.H.; KLEIN-GUNNEWIEK, H.; KOMAROV, A.S.; MOLINA, J.A.E.; MUELER, T.; PARTON, W.J.; THORNLEY, J.H.M. \& WHITMORE, A.P. A comparison of the performance of nine soil organic matter models using datasets from seven long-term experiments. Geoderma, 81:153-225, 1997.
TORNQUIST, C.G.; GASSMAN, P.W.; MIELNICZUK, J.; GIASSON, E. \& CAMPBELL, T. Spatially explicit simulations of soil $\mathrm{C}$ dynamics in Southern Brazil: Integrating Century and GIS with i-Century. Geoderma, 150:404-414, 2009.

TORNQUIST, C.G. Simulação da dinâmica do carbono orgânico do solo em escala regional: aplicação do modelo Century e sistemas de informações geográficas. Porto Alegre. Universidade Federal do Rio Grande do Sul. 2007. 156p. (Tese Doutorado) 
